\title{
Race and the Race for the White House On Social Research in the Age of Trump
}

\author{
Musa al-Gharbi ${ }^{1}$
}

\begin{abstract}
As it became clear that Donald Trump had a real base of political support, even as analysts consistently underestimated his electoral prospects, they grew increasingly fascinated with the question of who was supporting him (and why). However, researchers also tend to hold strong negative opinions about Trump. Consequently, they have approached this research with uncharitable priors about the kind of person who would support him and what they would be motivated by. Research design and data analysis often seem to be oriented towards reinforcing those assumptions. This essay highlights the epistemological consequences of these tendencies through a series of case studies featuring prominent and influential works that purport to explain the role of race and racism in the 2016 U.S. presidential election. It demonstrates that quality control systems, which should catch major errors, seem to be failing in systematic ways as a result of shared priors and commitments between authors, reviewers and editors - which are also held in common with the journalists and scholars citing and amplifying this work - leading to misinformation cascades. Of course, motivated reasoning, confirmation bias, prejudicial study design, and failure to address confounds are not limited to questions about Trump - however they seem to be particularly pronounced in this case due to the relative homogeneity and intensity of scholars' views about this topic as compared to other social phenomena. "Trump studies," therefore, provides fertile ground for exploring how social research can go awry - and the consequences of these failures -- particularly with respect to work on contentious and politically-charged topics.
\end{abstract}

Suggested citation: al-Gharbi, Musa (2018). "Race and the Race for the White House: On Social Research in the Age of Trump." The American Sociologist (49)4: 496-519.

${ }^{1}$ Paul F. Lazarsfeld Fellow in Sociology, Columbia University Website: mussaalgharbi.com

Email: musaalgharbi@gmail.com 
Some degree of bias is inevitable in social research. We are all shaped by our limited experience, our personal commitments and aspirations, etc. - and these inform social inquiry in obvious and subtle ways (Polanyi 1974). However, in a context where people with diverse and competing commitments, backgrounds and experiences are simultaneously exploring a particular issue, these errors should approach random distribution -- they would largely cancel each-other out. "Zones of agreement" should emerge in the process, forming a basis for reliable knowledge (Shi et al. 2019). However, in a world where everyone shares the same basic commitments, errors are not randomly distributed. They are far less likely to be recognized as errors and addressed at all - indeed, they are likely to cascade as an integral part of the "consensus" position, even giving rise to entire "null fields" of research (Ioannidis 2005).

Among social researchers, one commitment which virtually everyone seems to share is a passionate distaste for Donald Trump, his agenda, and what he seems to represent. As it became clear that Trump was a real contender for the Republican nomination, even as analysts consistently underestimated his prospects -- both in the primary and the general election - researchers became transfixed by questions of just who was supporting him and why (Samuelsohn 2016). These questions are perfectly reasonable and legitimate. The problem is that, as a result of their disgust with Donald Trump, many social researchers also seem to have developed strong assumptions about the type of person who would support him, and what they would be motivated by. These presuppositions have consistently undermined research about the President and his base. The most typical problems include:

- Failure to deal with obvious confounds

- Prejudicial study design

- Strange interpretations of data (apparently to make them fit with researchers' preferred theses)

- Uncharitable interpretations of the words and actions of Trump and (especially) his supporters ${ }^{1}$ or even outright misrepresentation through cherry-picking and editing (Alexander 2016).

Here, we will present a series of case studies exploring prominent examples of this phenomenon - particularly as it relates to the role of race (and racism) in the 2016 U.S. presidential election. On this point, an overwhelming consensus seems to have emerged that Trump voters were motivated largely (or even primarily) by anti-minority or white-supremacist sentiments. It will be demonstrated that the evidence scholars marshal in the service of these propositions is often weak, and abundant countervailing evidence to the consensus position has been chronically under-addressed, while alternative explanations for Trump's victory have been insufficiently explored - despite apparently resting on surer empirical footing.

The works discussed in the following pages will be by scholars I respect and even admire. Indeed, many are central to their respective fields. This is part of the point: the problem is not a matter of a couple bad apples or fringe scholars - it cuts to the heart of who we are and what we do as social researchers. The fact that the sort of errors described in the following pages could be made by people who obviously know better - with the resultant works endorsed by so many others who also know better -- strongly suggests motivated reasoning and confirmation bias are undermining the quality of our scholarship and the rigor of our critiques (Koehler 1993, Mahoney 1977). Indeed, research has shown that the more important an issue is perceived to be, the greater the risk that even grievous errors can go unnoticed or unaddressed (Wilson et al. 1993). However, the election of Donald Trump is not just an 'important issue' -- for many of us, and for many reasons, it is an outright crisis. However, this makes it all the more important to be clear-eyed and level-headed about how we got here. 


\section{THEORETICAL CONSIDERATIONS}

"The problem of knowledge is that there are many more books on birds written by ornithologists than books on birds written by birds and books on ornithologists written by birds." (Taleb 2010a, 108)

A key theme in the sociology of knowledge literature is that, contrary to idealized narratives of science as a dispassionate enterprise in search of objective truths, science is in fact deeply political on several levels. At the grand scale, ideological and cultural commitments inform who counts as trusted authorities and in virtue of what, standards of appropriate evidence for a claim, the appropriate scope and most pressing questions within a field of study, and even the structure of logical argumentation itself (al-Gharbi 2016a). Expertise and scientific consensus are established within a field, and presented to outsiders, through political processes internal to the discipline. At every stage in these processes there are power struggles between rival coalitions (Latour 1988), as well as with experts in adjacent fields (e.g. economists, political scientists, sociologists all aiming to shape policy on a particular issue, or competing for the same funding opportunities, etc.). Throughout, there is a parallel negotiation between the expert class and the politicians and publics they are supposed to advise and inform (Abbott 1988).

Yet another dimension of political contention is added for social scientific endeavors, because unlike in the case of most material sciences, the objects of study in social research fields (i.e. people) have agency. They have their own perspectives, interests, values, priorities and agendas which often diverge sharply from those of researchers (Meadow 2013). Recent scholarship has held that not only should these differences be recognized, 'insider expertise' should be privileged (Merton 1972). For instance, LGTBQ people are understood as having some kind of special knowledge or authority on queer issues, women on gender issues, racial and ethnic minorities (especially blacks) on race issues, Arabs and Muslims on the Middle East and terrorism, etc. ${ }^{2}$ This notion has undergirded much of the drive for diversity in social research fields.

Curiously, despite the fact that there is far less political diversity in social research fields than there is diversity in terms of gender, sexuality or even race (al-Gharbi 2018), the political positionality of scholars seems to rarely be considered as important or problematic. While scholars are obliged to concede that there is no superior race, class, gender, sexuality, or religion (except perhaps no religion), ${ }^{3}$ they are largely free to take for granted that their own political and ethical commitments are correct, and that those who diverge from them are both factually and morally 'in the wrong.' Indeed, while increased levels of education correspond to reduced levels of racial and ethnic bigotry, they also correlate with significantly higher levels of ideological prejudice (Henry \& Napier 2017). ${ }^{4}$

This political blind spot could be problematic for any discipline. However, it has particularly strong distortionary effects on the social sciences, because the subject of our fields is roughly identical to the content of politics: sorting out how society is best arranged. The discipline of sociology was established in the United States as a handmaid to the progressive reform movement (Abbott 2016, p. 49-50), and to this day there remains a strong element of activism undergirding American sociology and most other social research: scholars don't want to merely understand social problems, but to help address them as well (Smith 2014). ${ }^{5}$ As a result of social researchers' widespread certainty about the rightness of their political convictions (Abbott 2018), and the desire to leverage our research and expertise to intervene in sociopolitical disputes, it can be easy to temporarily lose sight of how complex, ambiguous and uncertain the phenomena we study are $^{6}$ Consider:

al-Gharbi, Musa (2018). "Race and the Race for the White House: On Social Research in the Age of Trump."

The American Sociologist (49)4: 496-519.

p. 2 
Even in "hard" disciplines such as physics, most experiments do not yield the expected result and replications frequently fail (Lehrer 2009). As we approach fields like biomedical research, the replication problem becomes far more severe - indeed, a majority of research efforts in these fields may be wasted by avoidable errors and poor experimental design (Munafo et al. 2017). Yet, despite our best attempts to emulate the material sciences (e.g. Levinovitz 2016), social research has not been able to demonstrate a comparable level of reliability and power as these other fields (Horgan 2013). Indeed, there is far less consensus on even foundational issues (Dunleavy, Bastow \& Tinkler 2014). The effect-sizes of most phenomena we study will be small almost by necessity (Gelman 2017), and it is likely that even many of these effects will ultimately prove to be false-positives (Engber 2017). In other words, social researchers should be cautious in making strong causal claims and skeptical when they encounter them from others.

Hence, there is a powerful a priori case for doubting deterministic narratives about the role of race and racism in the 2016 general election. This served as the point of departure for the case studies that follow.

\section{CASE STUDIES}

Co-occurrence searches on Google Scholar ${ }^{7}$ can help highlight the scale of the phenomenon this essay seeks to address. Restricting our analysis to 2016 and beyond, pairing "Donald Trump" with "racism" yields more than 19.7k articles published in journals, books, or cited in academic work (Google Scholar). Searching "Donald Trump" and "white supremacy" yields 5.9k results (Google Scholar) -"Donald Trump" and "xenophobia" nets 6.6k (Google Scholar); "Donald Trump" and "ethnic nationalism" brings in 651 results (Google Scholar). Even assuming some overlap between these, it is clear that an extensive literature has emerged analyzing the relationship between Trump and racism, culled from a wide array of fields, and produced in a relatively short amount of time (especially given how long it takes to publish academic research, the lag time until works show up in Google Scholar after publication, and the restrictiveness of the search criteria).

Having worked through the first ten pages of results for each of these (ten results per page), the titles, descriptions and abstracts of these works suggest that many scholars take it more-or-less for granted that Trump and his supporters are racist. A large number - even among those published in prominent journals - seem to have an explicitly partisan and activist orientation. None of the hundreds of works personally surveyed seemed to challenge prevailing narratives about Trump, his supporters, and their alleged racism. This essay drills into a sample from this literature and addresses its major themes - focused on works that have had demonstrably large impact both within the academy and beyond:

\section{Ta-Nehisi Coates, “The First White President,” The Atlantic, October 2017.}

It may seem strange to lead with Ta-Nehisi Coates in an article discussing problems with social research. One anticipates a reply that runs basically, "so what if Ta-Nehisi's research isn't rigorous by the standards of social science? That's not his job. He's a public intellectual, not an academic." However, Coates' work greatly influences the academy, and informs a good deal of research in the humanities and social sciences. Consider:

Studies suggest that a majority of journal articles are likely never read by anyone other than their editors and authors (Eveleth 2014). 82\% of articles in the humanities -- and roughly a third of all articles published in the social sciences -- are never cited, even once (Remler 2014).

\footnotetext{
al-Gharbi, Musa (2018). "Race and the Race for the White House: On Social Research in the Age of Trump."

The American Sociologist (49)4: 496-519.

p. 3
} 
These numbers, as bad as they seem, would actually look dramatically worse if self-citations were excluded from consideration (Shema 2012). In contrast with this dismal state of affairs for most social research, Coates' work is widely cited in academic literature (Google Scholar). His memoir, Between the World and $M e$, is among the most frequently-assigned common readings for incoming freshmen at universities nationwide (Randall 2017), and his work is assigned as required reading for courses across a wide range of disciplines (Google). He regularly participates on panels and delivers keynote addresses at universities, and served as a visiting scholar at MIT from 2012 through 2014 (Smith 2017). He recently signed a three-year contract to teach journalism courses at New York University - placing him in a pedagogical position at one of the top-ranked journalism programs in the nation (Roy \& Siu 2017), and at one of the most prestigious universities in the world (Times Higher Education, 2017). In short, Ta-Nehisi Coates has already been far more successful and influential in the academy than most 'real' academics could plausibly aspire to be over the course of their careers.

Coates' essay (2017b), "The First White President," is far more likely to be read and cited by academics - and to inform academic thinking on these issues - than most other instances of scholarship that could be produced from the professional literature. It has already been cited at least 123 times (Google

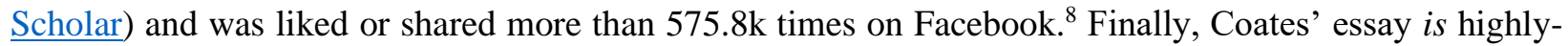
representative of a swath of academic literature that's out there - for instance, his central thesis is roughly the same as that of Emory sociologist Carol Anderson's (2017) book, White Rage: The Unspoken Truth of our Racial Divide. ${ }^{9}$

Coates argues that while many pundits have pinned the election outcome on the "white working class' (e.g. Cohn 2016) ${ }^{10}$ this is an overly-narrow reading of the race. In fact, he asserts, Trump decisively won among virtually all whites - cutting across income, gender, education, and geographic lines. ${ }^{11}$ From there, Coates essentially imputes causation from correlation: (i)Trump repeatedly made racially/ culturally inflammatory remarks; (ii) Trump won the white vote; (iii) Therefore, Trump won the white vote because of his appeals to white supremacy. In his telling, white Americans rose up in 2016 to dismantle the legacy of America's first black president, Barack Obama (Coates 2017a) — and to reclaim what is rightfully 'theirs.' Trump was elected primarily because of racial resentment, and he maintains his hold on power by playing to Americans' latent sympathies with white supremacy. Despite the popularity of this thesis, it suffers from several serious problems:

First, many of the white voters who proved most decisive for Trump's victory actually voted for Obama in both 2008 and 2012 (Uhrmacher, Schaul \& Keating 2016). Indeed, according to one Democratic political firm, the Global Strategy Group, these defections explain more than $70 \%$ of why Clinton lost (Roarty 2017). ${ }^{12}$ If the white voters who ostensibly decided the 2016 election were horrified at the very prospect of a black president, it is unclear why they would have supported Barack Obama's initial campaign. Similarly, if they were committed to undermining and dismantling the legacy of the first black president, it is not clear why they would have voted to give him four years to further entrench his agenda rather than simply voting for Mitt Romney in 2012. Apparently, instead of resisting Barack Obama in 2008 or 2012, they chose to act on their racial grievances years later, in a race between two white people. Coates et al. portray the 2016 election as being fundamentally 'about' Barack Obama and what he allegedly represents, rather than the (un)desirability of Hillary Clinton and/or Donald Trump. Yet in the lead-up to the election, Obama was far more popular than both Clinton and Trump - indeed, he grew more popular over the course of the 2016 cycle, even as the appeal of his would-be successors plummeted (Tesler 2016). ${ }^{13}$ All of this seems inconsistent with the notion that the election was an uprising against Barack Obama - as a symbol or a politician. ${ }^{14}$

al-Gharbi, Musa (2018). "Race and the Race for the White House: On Social Research in the Age of Trump."

The American Sociologist (49) 4: 496-519. 
Second, Trump did not mobilize or energize whites towards the ballot box (Mellnik et al. 2017). Their participation rate was roughly equivalent to 2012 - and lower than in 2008. In fact, whites actually made up a smaller share of the electorate than they had in previous cycles, while Hispanics, Asians and racial "others" comprised larger shares than they did in 2012 or 2008. This seems inconsistent with the thesis that Trump spearheaded an ethnic nationalist uprising.

Even if we overlook Obama's continued popularity and whites' tepid participation, at the very least the 'white supremacy' thesis would seem to entail Trump winning a larger share of those whites who did turn out to vote. In fact, Trump won a smaller share of the white vote than Mitt Romney did in 2012 (alGharbi 2017b). ${ }^{15}$ However, he outperformed his predecessor with Hispanics and Asians, and won the largest share of the black vote of any Republican since 2004. Given Trump's lower share among whites, it was likely these gains (and Democrats' attrition) among people of color that put Trump in the White House. Coates et al. therefore seem committed to arguing that the millions of these blacks, Latinos and Asians who voted for Trump were also primarily or exclusively motivated by 'white rage' or their commitment to white supremacy - or else conceding that it is possible to vote for Trump for other reasons (and of course, if this is true of minorities, it stands to reason what whites could be similarly motivated by other factors).

Now, there might be some way to make the 'white supremacy' / 'white rage' argument work while accounting for these apparent confounds - but this is not something that most proponents are doing. Although the hypothesis is intended to explain voting behavior (i.e. why Trump won), researchers largely ignore most of the critical data about who actually voted, and for whom. They run regressions testing correlations between various demographic characteristics and political attitudes in pre-election surveys, but fail to check if and how the resultant picture lines up with the available information on how people actually voted. In those too-rare instances where researchers acknowledge apparent confounds for claims about Trump voters' alleged racism, the most common tactic is to say something along these lines:

"The explanation that Trump's victory wasn't an expression of support for racism because he got fewer votes than Romney, or because Clinton failed to generate sufficient Democratic enthusiasm, ignores the fact that Trump was a viable - even victorious - candidate while running racist primary- and general-election campaigns. Had his racism been disqualifying, his candidacy would have died in the primaries (Serwer 2017)."

There are three big problems with this line of thought:

First, there is a demographic confound. Again, Trump not only garnered stagnant turnout and a smaller vote-share among whites relative to Mitt Romney - he was nonetheless able to win because he also received a larger share among Asians and Hispanics (who did turn out in higher numbers), not to mention African Americans. Should we assume that Asians, Latinos and blacks were also motivated primarily by racism simply because they did not find Trump's rhetoric (about China, Mexicans and Muslims) disqualifying? This is an implication of the argument.

Second, it is just a logical error to assert that because Trump's 'racist' rhetoric was not disqualifying, Trump voters therefore supported him primarily due to his racial appeals. As Van Jones aptly points out (Martinez 2017), Trump supporters regularly and forcefully rejected or expressed disquiet with many of his racialized statements or policy proposals, but voted for him nonetheless because there were other parts of his platform they found it essential to support, or because he was just viewed as the least-worst option relative to Hillary Clinton. We can underscore this point with the help of a simple "turnabout test" (Tetlock 1994): 
Hillary Clinton has a long record of foreign policy hawkishness - even surpassing most of the Republican primary candidates in the 2016 election cycle (al-Gharbi 2015a). Her Democratic National Convention was noted for its emphasis on patriotism, supporting the troops, confronting America's enemies, etc. to a point where many pundits observed that it actually seemed like a Republican event (e.g. Gaouette 2016). Many prominent neoconservatives outright endorsed Clinton as the best candidate in either party to promote their agenda (Norton 2016). Clinton actively sought out the endorsement of controversial figures like Henry Kissinger and repeatedly bragged about their support on the campaign trail and in debates (Grandin 2016). ${ }^{16}$ During the primaries, she relied on the same foreign policy consulting firm as hawkish Republican candidates Marco Rubio and Ted Cruz (Fang 2015). Her general-election national security advisory team was drawn heavily from people who oversaw some of the greatest excesses of the George W. Bush administrations (Jilani, Emmons \& LaChance 2016). Should we assert that because Clinton's well-established record of hawkishness was not disqualifying, that her supporters must have voted for her because they, themselves, are hawks? Or to be less charitable: did most Democratic voters support Clinton because they actively endorse the killing, traumatization and immiseration of others abroad (mostly people of color, often of low socio-economic status) in the name of ill-defined 'U.S. values and interests'? No. For most Clinton voters this was an aspect of her record they found troubling, perhaps abhorrent, but not disqualifying. ${ }^{17}$

Was race a critical factor in the 2016 election? Undoubtedly. But of course, this can be said of virtually every electoral cycle in American history - including the 2008 and 2012 races which resulted in the election and re-election of Barack Obama. The specific ways race influences politics are far more complex and unpredictable than the analyses of Coates and his fellow travelers seem to suggest ${ }^{18}$ - even among those who voted for Trump. Indeed, Hillary Clinton herself has a troubled history on racial issues which many black voters did find disqualifying (al-Gharbi 2016b), perhaps helping to explain the depressed turnout among this constituency - or even Trump's gains among blacks (relative to Romney).

Finally, looking at whites' stagnant turnout in 2016 and Republicans' lowered vote share among whites as compared to 2012 -- it could be that Trump's inflammatory rhetoric was, on balance, a drag on his candidacy among white voters, rather than being the key to his electoral success. In order to explore this possibility, researchers would have to turn their attention away from the motivations of whites who did vote for Trump, and towards the large majority (63\%) of eligible non-Hispanic white voters who did not (Figure 1).

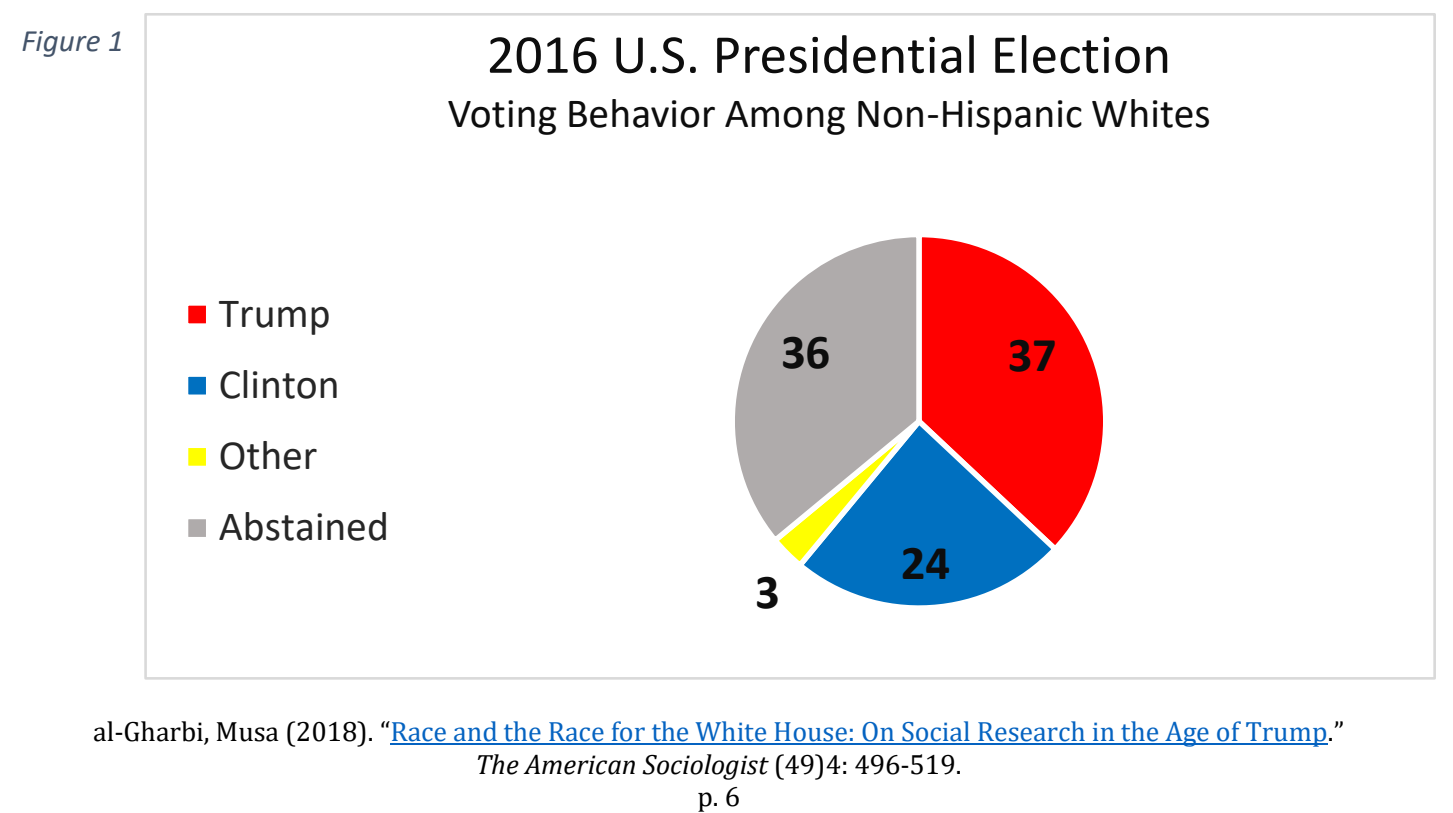


For instance, even if it was assumed that $100 \%$ of those whites who voted for Trump were motivated primarily by racial resentment - a claim which has no empirical basis to be clear - one would still be unable to make sweeping generalizations about white people on the basis of these votes. Nearly as many eligible non-Hispanic whites chose to abstain (36\%) as those who voted for Trump (37\%). This should raise grave concerns about participation bias in interpreting what the election "means" on the basis of Trump votes (Groves \& Peycheva 2008, Paleologos et al. 2018) - especially given that an additional $27 \%$ of non-Hispanic whites explicitly rejected Trump by casting their votes for other candidates (Clinton, Johnson, Stein, McMullin).

Another turnabout test can help underscore the problems with making sweeping claims on the basis of such a dubiously representative sample: according to Bureau of Justice statistics, up to a third of all African American males can expect to be incarcerated at some point in their lives (Bonczar 2003). On a pie chart, the wedge for "black men expected to "do time"" would look very similar to the red area in Figure 1. Should we assume on this basis that most black men are criminals? Of course not. Nor can we declare an epidemic of racism among whites because $37 \%$ of eligible non-Hispanic white voters cast their ballots for Trump (again, setting aside the grievous problems with imputing racist motives to those who did support the Republican candidate simply on the basis of their vote). ${ }^{19}$

In short, the 'white supremacy' thesis not only lacks empirical support, it is confounded by the very data it seeks to explain. Researchers often attempt to circumvent these realities by conflating (often begrudging) tolerance for Trump's racialized remarks and policies with active endorsement of his racial appeals. Not only is this illogical, it is inconsistent with the way progressives seem to interpret support for Hillary Clinton given her liabilities. Yet even working from within this model, it would actually be consistent with the data to assert that most whites did find Trump's rhetoric disqualifying. The 'white supremacy' thesis therefore fails even if the conflation between tolerance and endorsement were allowed to stand (although it should not be allowed to stand).

\section{Thomas Wood, "Racism motivated Trump voters more than authoritarianism," Washington Post, 17 April 2017.}

This article was written by an assistant professor of political science (Ohio State) and published in the Washington Post "Monkey Cage" blog. All articles published on this site are curated and edited, not just by academic political scientists, but by some of the most prominent scholars in the field (Sides 2013). Therefore, although this essay was not a peer reviewed journal article, it was, in fact, reviewed by Wood's political science peers prior to publication at the Monkey Cage. ${ }^{20}$ The essay has had a demonstrable academic impact - cited at least 31 times so far (Google Scholar), including in the American Sociological Review and the British Journal of Sociology -- among the top journals in the field of sociology. The essay has had a demonstrable public impact as well, with more than 71.2k shares on Facebook.

Wood seeks to challenge popular narratives about Trump voters being driven to the candidate due to their support of authoritarianism (e.g. MacWilliams 2016). Utilizing data from the American National Election Studies (ANES) Time Series Study, he found that Trump voters seem to be less supportive of authoritarianism than those who voted for Romney or McCain (Figure 2). ${ }^{21}$ 


\section{Authoritarianism and the GOP Presidential Electorate: 2000-2016}

Light bar reports percentage opting for non-authoritarian option

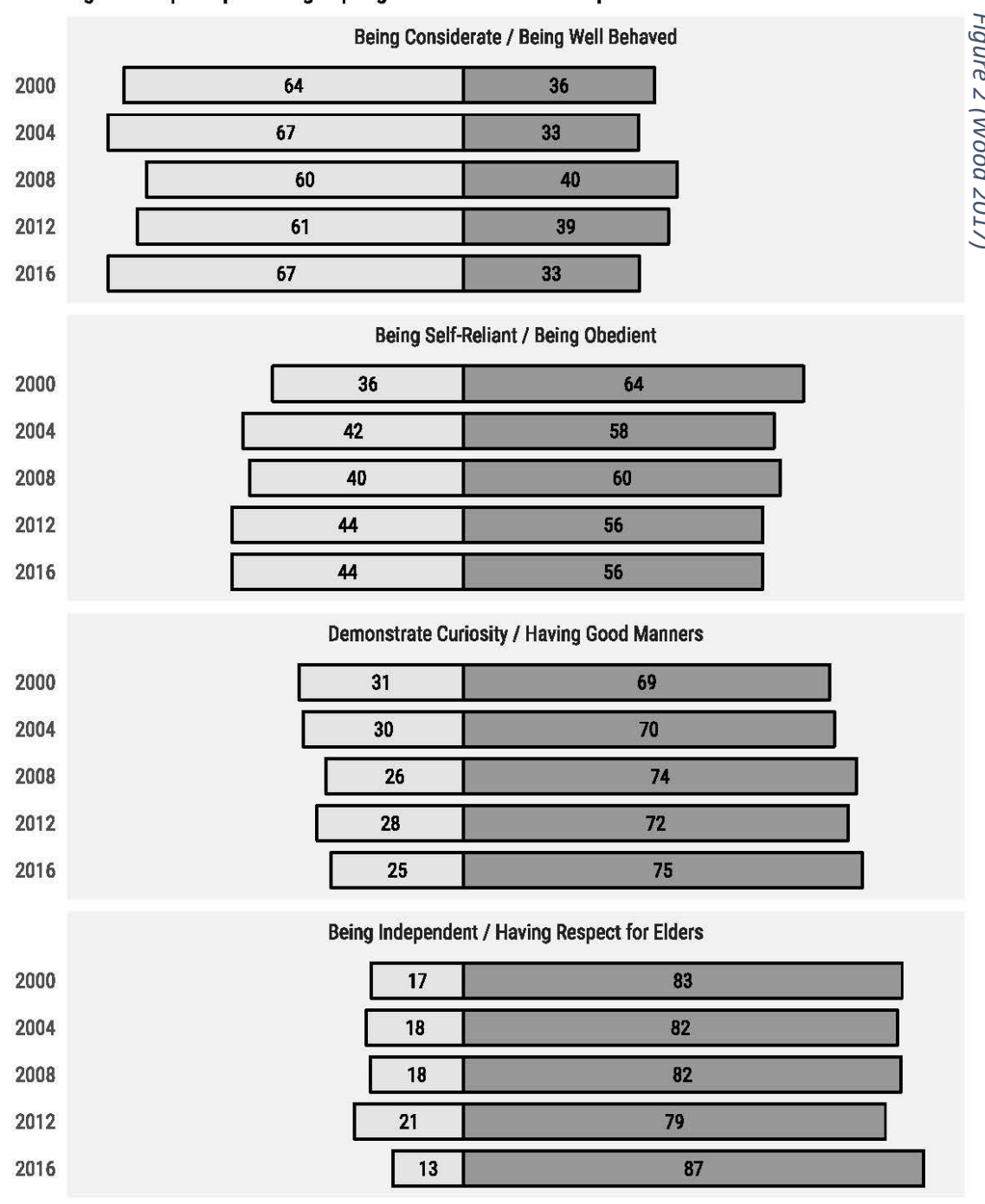

Source: 2000, 2004, 2008, 2012, 2016 ANES Time Series

Wood then posits that, given Trump's repeated use of racially inflammatory language throughout the primary and general election, racism may better explain why a voter would support Trump over Clinton. In order to test this hypothesis he developed a "symbolic racism" scale (SRS) and explored how white ANES respondents' scores on that scale corresponded to support for the Democratic and Republican presidential candidates, from 1988 through 2016.

For the moment, we can set the well-known problems with attributing motives to political positions on the basis of measures like "symbolic racism" scales (e.g. Sniderman \& Tetlock 1986). ${ }^{22}$ 
And although both of these claims are contestable, we'll just grant for the sake of argument that Dr. Wood's ANES-derived scales are sufficiently accurate measures of racist and authoritarian tendencies in the voters sampled, and that his sample is sufficiently representative to allow for sound generalizations about Trump and Clinton voters on the basis of his study. Figure 3 presents Wood's visualization of his findings, as presented in the Washington Post.

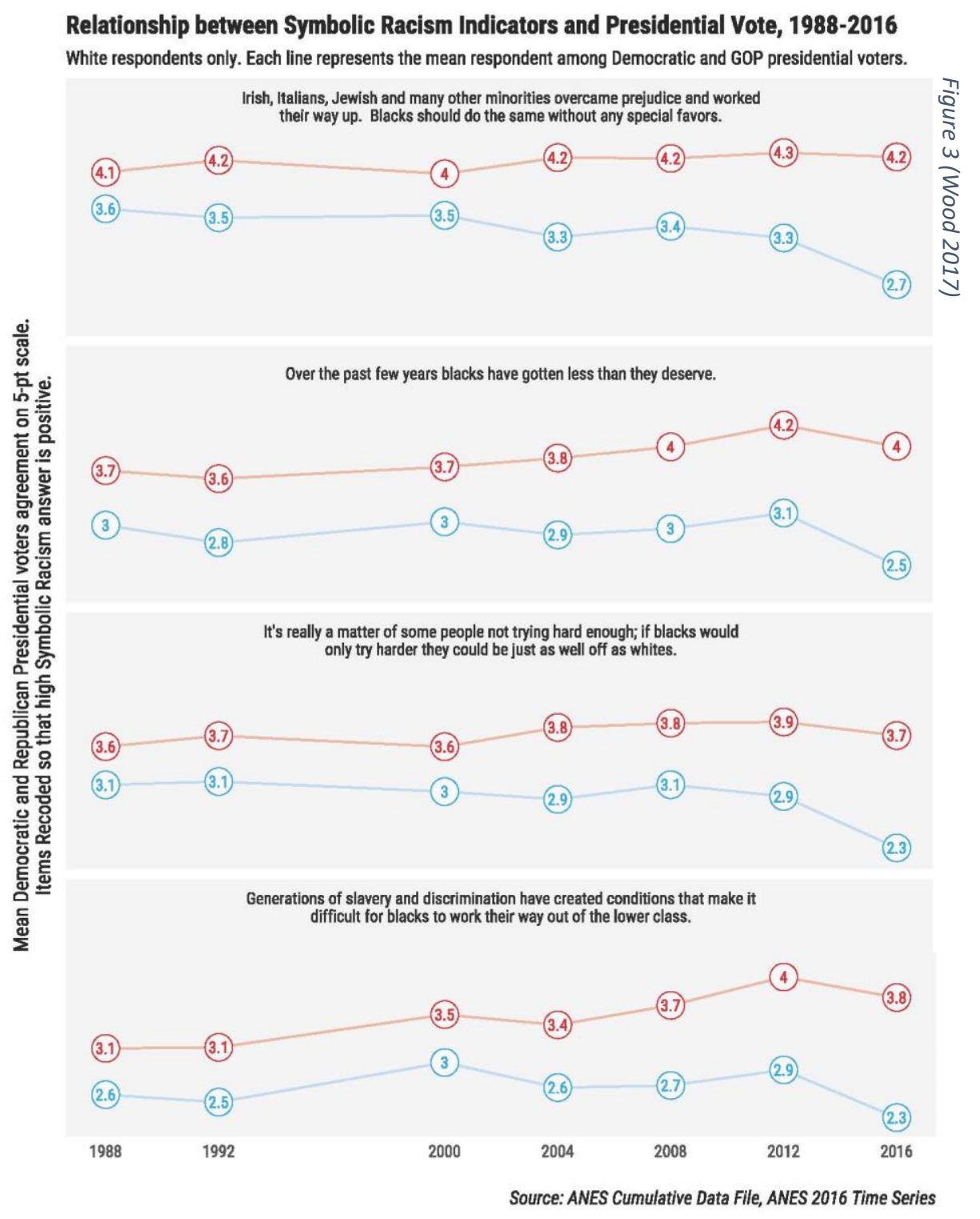

One thing readers may immediately notice, which ends up being the centerpiece of his argument, is that the gap between Democrats and Republicans on his symbolic racism measures was larger in 2016 than it had been in previous years - 
suggesting that race likely played a much bigger role in the most recent election than it had in prior cycles. This is an interesting finding which we'll return to momentarily. In the meantime, however, it should be noted that across all measures the longitudinal trend is roughly the same among supporters of the Republican and Democratic candidates between 2004 and 2016: endorsement of 'racist' attitudes increased substantially among all voters during the Obama years $(2008,2012)$ and then dropped among all voters in this most recent cycle. That is, Wood's data does not suggest that Trump voters were especially motivated by racism. Instead, among supporters of both the Democratic and Republican candidates, whites were actually less likely to endorse symbolically racist attitudes than they were in 2012. In other words, according to Wood's own data, whites who voted for Trump are perhaps less racist than those who voted for Romney. The same holds among whites who voted for Clinton as compared to those who voted for Obama (in either term).

This is truly a newsworthy and provocative finding about Trump voters: not only were they less authoritarian than Romney voters, but less racist too! Had the findings been presented this way, Wood's report certainly would have served as a springboard for rich discussion and helped to push research on Trump voters in new and interesting directions. Unfortunately, although his analysis of authoritarianism focused on variation among Republicans over time, Wood curiously decided to adopt an alternative analysis with respect to understanding the role of race $^{23}$ - in particular, focusing on the gap between Democrats and Republicans in 2016, in the service of a conclusion his data do not support.

Wood asserts, “Since 1988, we've never seen such a clear correspondence between vote choice and racial perceptions." He goes on to concede that, "The biggest movement was among those who voted for the Democrat, who were far less likely to agree with attitudes coded as more racially biased." This is an understatement: across all measures, Republican voters' SRS trend was actually towards convergence with the other party. Change in Democrat-voters' sentiment drives the entire divergence effect Wood refers to...in an article that is supposed to explain Trump voters. Statistically speaking, the decline in authoritarianism was greater than the decline in racism, while the decline in endorsing symbolic racism among Democrats was larger than the decline among Republicans. So even through there were actually declines across the board, in a multivariate analysis symbolic racism could be made to seem relatively more significant for Republicans - if that was the image one was actively trying to convey. It seems bizarre and incoherent to point to an apparent decline in endorsement of racism among Republicans in 2016 in order to demonstrate that Trump voters are particularly racist - yet that is precisely what Wood did.

To elaborate: the gap between Democrats and Republicans was caused, not because Trump voters were more likely to endorse symbolic racism than Republicans in previous cycles (again, the exact opposite seems true), but instead because Democrats went out of their way to emphasize just how non-racist they were in 2016 surveys - (ostensibly) rejecting symbolic racism more powerfully than they ever have in the time 28 years of data presented. In fact, Wood's data suggest that racist sentiment among Democrats actually increased in 2008 with Barack Obama on the ballot, and more-or-less held at that higher level in 2012. This renders the unprecedented drop among Democrats in 2016 even more interesting. Indeed, if Wood wanted to focus on the change in the partisan gap among SRS indicators, given that Democrats are the ones driving that effect, the article should have been about them. Such a story would not suggest that Trump voters are especially motivated by racism - again, Wood's own data confound that claim. Instead, perhaps Democratic voters were particularly motivated by anti-racism (McWhorter 2015). ${ }^{24}$ Wood could have still said something like "moving from the 50th to the 25th percentile in the SRS scale rendered whites 20 percent more likely to vote for Clinton" - only now there wouldn't be misleading insinuations about Trump being made in the process.

al-Gharbi, Musa (2018). "Race and the Race for the White House: On Social Research in the Age of Trump."

The American Sociologist (49)4: 496-519.

p. 10 
On the other hand, if Wood really wanted to make the article 'about' Trump voters, his results should have been described in a completely different manner. For instance, the "unprecedented" partisan divide among SRS indicators should not have been part of the story at all: given that it is entirely the product of a severe longitudinal aberration among supporters of the Democratic candidate, it isn't clear what (if anything) can be inferred about Trump voters from the gap. With regards to the relative significance of authoritarianism and racism, Wood could have more legitimately asserted that "Trump voters seem to be more strongly influenced by racism than authoritarianism - although they were less motivated by either of these factors than Republican voters have been in previous cycles." This latter part, which Wood omitted, is actually the significant story in his data on Trump voters (as compared to those who supported previous Republican candidates). ${ }^{25}$ Wood should have also been more explicit about how much of the total variance in voting behavior was explained by the factors he focused on (as reflected in the $\mathrm{R}^{2}$ of his regressions). It seems likely that a majority of the variance would remain unexplained by his authoritarianism and/or racism scales.

Following these standard best-practices would have had the added virtue of drawing readers' minds to the following question: "if both racism and authoritarianism seemed less appealing to Trump voters than to previous Republican constituencies - and if these factors don't explain most of the variance in voting behavior anyway - is there some other (omitted) variable that may explain Trump voters even better?"26 This is important because, over and above the problems with Wood's interpretation of his data, there is the problem that the study design is prejudicial.

In this work, and others in the genre, it seems taken for granted that Trump voters must have been motivated by some 'bad' factor (poverty, ignorance, irrationality, authoritarianism, racism, xenophobia, sexism, etc.) and the task of social researchers is merely to identify which of these traits best explains the data. ${ }^{27}$ Indeed, there is a long history in social research of pathologizing libertarians, conservatives and populists - essentially describing views that diverge from researchers' own political preferences as resulting from ignorance, error or character defects (Duarte et al. 2014). Meanwhile, there is relatively little research discussing the extent to which Clinton voters were motivated by negative impulses (the same ones or others). It is implied that, by contrast, they must have been guided primarily by benign traits such as love for others, patriotism, knowledge of the issues, rational self-interest, etc. (Stanovich 2017).

\section{Arlie Hochschild, Strangers in Their Own Land: Anger and Mourning on the American Right, September 2016.}

Hochschild's book was published two months prior to the 2016 election, and it is not technically about that election. However, it is worth examining this work in closing for a few reasons. First, it had a major impact of how people understood the outcome of the 2016 election. The perceived insight and prescience of the work as it relates to the election of Donald Trump helped elevate it into being a New York Times bestseller and National Book Award finalist. These same perceptions likely help explain why it is so widely assigned as a required reading in course syllabi, in sociology departments and beyond (Google). It has been cited more than 1.2k times (Google Scholar), often in works about the election. This is likely in part because Hochschild herself has repeatedly asserted that Strangers in their Own Land robustly explains Donald Trump's appeal (Hochschild 2016b). In subsequent peer-reviewed articles she has implored other social researchers to follow the methods she laid out in Strangers in their Own Land in order to gain further insight into the "rise of the right" (Hochschild 2016c). Since the election, many social researchers and journalists have attempted to do just this - flocking to regions Clinton lost, "on safari in Trump's America" (Ball 2017), in an attempt to figure out how Democrats can turn things around in 2018 and 2020.

al-Gharbi, Musa (2018). "Race and the Race for the White House: On Social Research in the Age of Trump."

The American Sociologist (49)4: 496-519.

p. 11 
Given that we have so far explored the many ways statistical and historical facts have been distorted to caricaturize Trump supporters as racist (not to mention ignorant, irrational, misogynistic, etc.), ethnography may seem like a far more reliable method for understanding Trump voters and their motivations. Researchers can directly observe the milieu of their subjects. Rather than the simple questions pollsters rely on, ethnographers can have repeated in-depth conversations with their subjects - and follow the discussion wherever it leads. Certainly, in many instances ethnographic research can promote key theoretical insights or provide critical context to quantitative data (Wilson \& Chadda 2009). However, there is little reason to believe that ethnographic methods are, on balance, more reliable than quantitative or historical approaches for understanding contentious political issues.

Contemporary research suggests that partisanship affects our cognition at a fundamental level potentially shaping our memories and evaluations of events, and at times, even coloring sensory perceptions (Van Bavel \& Pereira 2018). These are the very foundations upon which ethnography is built. Indeed, given the highly subjective nature of the ethnographic encounter, the method may be even more vulnerable to certain forms of bias, especially when researchers are seeking to understand perceived socio-political rivals, with the aim of advancing a particular socio-political agenda (Avishai, Gerber \& Randles 2013) ${ }^{28}$ Yet, even as these commitments systematically distort or obscure critical details of their cases, ethnographers can gain a strong erroneous conviction that they truly understand 'the other side' as a result of the intimate nature of their research (Martin 2016). Seduced by the power of narrative, both the researcher and their audience can significantly overestimate the reliability and generalizability of the resultant study (Taleb 2010b). This certainly seems to be the case with Strangers in Their Own Land.

Hochschild conducted forty "core interviews" (Hochschild 2016a, 247-50) -- all with white Tea Party supporters, concentrated in one narrow region (Lake Charles) of a single state (Louisiana). This is an extremely small and homogenous sample for explaining why some 63 million people, from all across the country and all walks of life, cast their ballots for Donald Trump. Indeed, as we have previously explored, the race was likely decided by people who voted for Obama in the previous election(s) but flipped for Trump in 2016. Few of these voters would have been staunch Tea Party supporters (they may even have very negative views about the Tea Party). And again, many of the most critical defections were not from whites at all. Were it not for Republican gains (and Democratic losses) among blacks, Hispanics and Asians, Trump likely would have lost -- given that he actually won a smaller share of the white vote than Mitt Romney. Yet there does not seem to be one single county in the state Hochschild studied that flipped from Obama to Trump (Figure 4). 


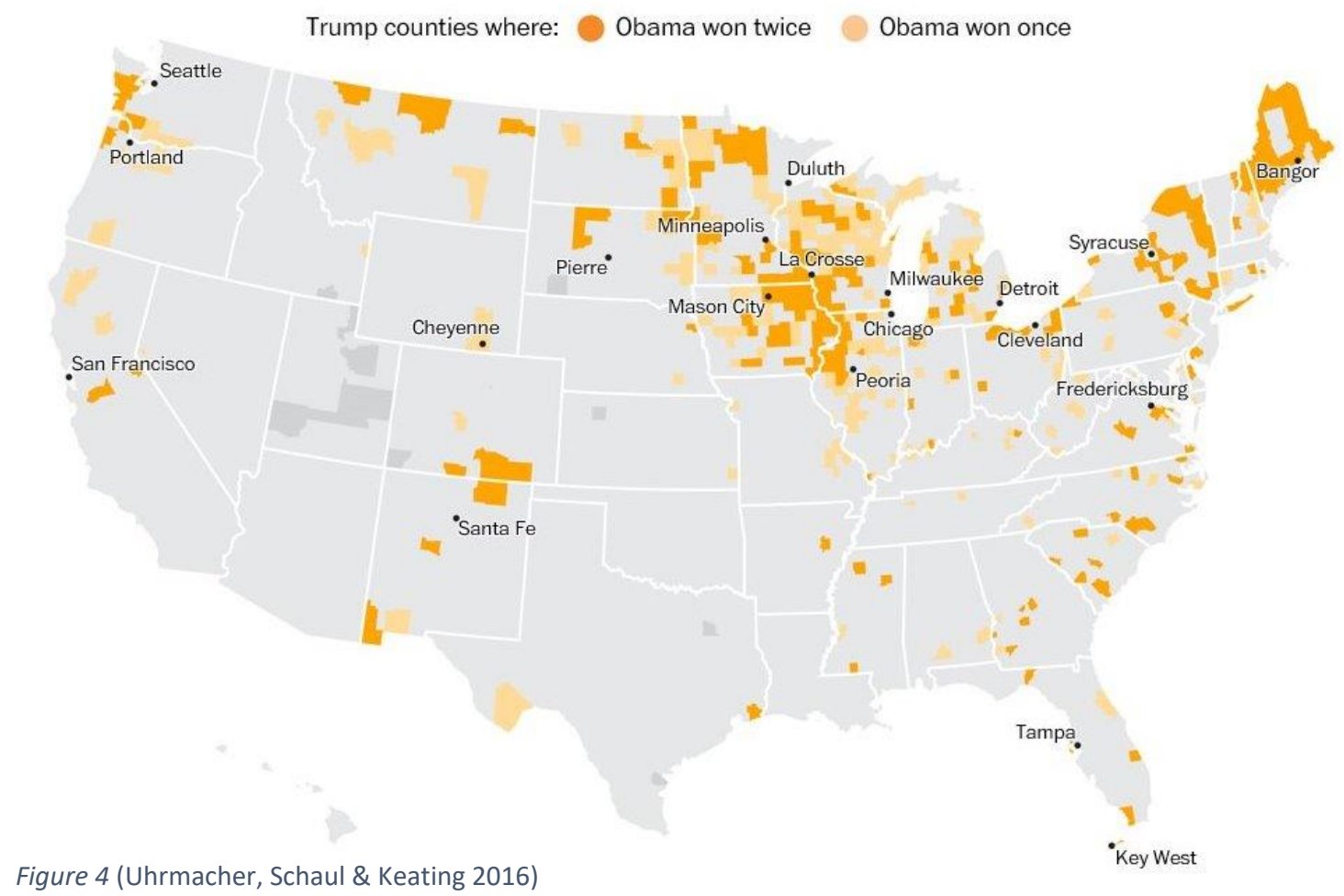

Figure 4 (Uhrmacher, Schaul \& Keating 2016)

Indeed, by her own reckoning, only about $11 \%$ of white Louisiana voters supported Obama in 2012. In 2011, up to 50\% of Louisianans supported the Tea Party. The region is described by Hochschild herself as the "geopolitical heart of the right" (p. 11-2). Simply put: these votes were not decisive in the 2016 election - there was no real contest for the Louisiana at all. And so, empirically speaking, it is not clear how Hochschild's project -- which basically attempts to understand why whites in a solidly-red state vote Republican - would explain much about why so many former Obama supporters, many of them minorities, voted for Donald Trump over Hillary Clinton in 2016. This is perhaps the most substantive question for understanding why Trump won, and it is not addressed in her book - whatever its other merits. Yet, the narrative Hochschild weaves is so seductive and compelling (especially for progressives) that questions of representativeness and generalizability seem to be taken for granted - to include at times by Hochschild herself - in discussions about the book and its relevance for understanding Trump's appeal.

Moreover, while Hochschild's subjects are often highly compelling and insightful when speaking for and as themselves in the work, her analyses of these accounts frequently seem to suffer from political bias. Hochschild's treatment of her subjects is compassionate, but essentially condescending (Lozada 2016). Her main project is to understand the "emotional draw" of right-wing politics (Hochschild 2016a, 247), in part because she seems to take for granted that her subjects' preferences could not be grounded in a view of the world that is as logical or informed as that of progressives. ${ }^{29}$ Indeed, the book is fundamentally structured around resolving the "great paradox" of why people who should support state programs, interventions and regulations do not. That is, Hochschild is convinced from the outset that she understands her subjects' best-interests better than they, themselves, do. That assuredness never wanes - despite her frequent criticisms of the ways other progressives demean and disrespect these constituents. 
With regards to the core contribution of the book, the 'deep story' of why her subjects support the Tea Party (and Trump), Hochschild seems to put great weight on the fact that her respondents widely endorsed the general picture she proposes - particularly the sense of frustration and marginalization that comes through in the narrative. However, the fact that they support the broad picture does not necessarily entail that they endorse every particular component of that narrative. Indeed, parts of the 'deep stories' Hochschild presents to her respondents seem to be intentionally leading. For instance (emphasis added):

“...You're a compassionate person. But now you've been asked to extend your sympathy to all the people who have cut in line ahead of you. And who's supervising the line? It's a black man whose middle name is Hussein. He's waving the line cutters on. He's on their side. He's their president, not yours. What's more, all the many things the federal government does to help them don't help you. Should the government really help anyone? Beyond that, from ahead in line, you hear people calling you insulting names: 'Crazy redneck!' 'White trash!' 'Ignorant southern Bible-thumper!' You don't recognize yourself in how others see you. You are a stranger in your own land. Who recognizes this?" (Hochschild 2016b, 686).

Every component of a "deep story" should be more-or-less essential. Yet evoking Obama's race and his middle name seems unnecessary here, an attempt to bait respondents into tacitly endorsing racially inflammatory language. The implication seems to be that if they do claim to "recognize themselves" in the general story, then they must have a problem with the specific fact that our president was "a black man," and one whose middle name happens to be "Hussein." Does Hochschild really believe that her respondents would find the bolded text integral to the story? Would the story have been less likely to resonate with them if the relevant passage simply read: “... But now you've been asked to extend your sympathy to all the people who have cut in line ahead of you. And the line supervisor seems to be just waving the cutters on. He's on their side..."? Would they spontaneously add, "and one more thing, the line supervisor is a negro with a Muslim name!" This seems unlikely.

Indeed, if the "deep story" is supposed to explain why Louisianans support the right, then presumably this tale would stretch beyond Barack Obama's presidency in both temporal directions. The geopolitical trends that left communities like Lake Charles behind began in the mid- 90's. The oppositional attitude towards the institutions, forces and actors perceived to be behind those trends also began to escalate at this time (Foa 2016). Louisiana didn't flip to the Republicans because of Obama - it has remained "red" for every presidential election after 1996. Therefore, highlighting the fact that the "line supervisor" at the time was a "black man whose middle name is Hussein" seems to substantially undermine the "depth" of her narrative - reducing a story that has been ongoing for much of her subjects' lives into something that is fundamentally 'about' Barack Obama and what he allegedly represents. Similarly, Hochschild's "deep story" would presumably have remained just as true if Hillary Clinton had won in 2016 - which she almost did -- therefore it seems strange to impute said "deep story" as explaining Trump's victory.

At times, Hochschild's project even seems exploitative: In a break with her groundbreaking previous work, the goal of Strangers in their Own Land is not so much to understand these people on their own terms, for their own sake - or to shine a light on the challenges they face, and their needs as they understand them. Instead, Hochschild's Tea Party supporting subjects and their stories are used as a means to political ends -- ones which they would never, themselves, endorse (Ray 2017): Hochschild wants to stall the "rise of the right"; she wants to help progressives understand how to advance their agenda and candidates in red states; she wants to neutralize the appeal of Donald Trump. 
Hochschild seems to paternalistically believe that securing these political objectives would benefit her subjects in the end - irrespective of their own preferences. However, this goal seems secondary at best in reading the book. Although she typically refers to subjects as her "Tea Party friends" -- in the end they do not seem to be on the same page, and they are not on the same team.

\section{CONCLUSION}

“...[T]he tendencies operating in 1948 electoral decisions not only were built up in the New Deal and Fair Deal era but also dated back to parental and grandparental loyalties, to religious and ethnic cleavages of a past era, and to moribund sectional and community conflicts. Thus in a very real sense any particular election is a composite of various elections and various political and social events. People vote for a President on a given November day, but their choice is made not simply on the basis of what happened in the preceding months or even four years; in 1948 some people were in effect voting on the internationalism issue of 1940, others on the depression issues of 1932 and some, indeed, on the slavery issues of 1860." (Berelson, Lazarsfeld \& McPhee 1986, 315-6).

The case studies presented here suggest serious, perhaps endemic, flaws on social research about the 2016 U.S. presidential election. Specifically, although the evidence presented here suggests that the role of race has been widely overblown and misunderstood with respect to Trump's victory, social researchers nonetheless systematically represent Trump voters, and whites more broadly, as white supremacists in virtue of their (presumed) support for the President. There is a Manichean subtext, with 'evil' racists complicit in a depraved regime, v. the 'good' progressives who dutifully voted for Hillary Clinton (Hamid 2016). In the case of Hochschild, we see a variant on this narrative: Trump's supporters aren't bad people, they're just victims and hapless dupes of the Republican Party and their 'fascist' leader. It is easy to see how these are edifying stories for progressives - which social researchers overwhelmingly are - but these tendencies are also deeply pernicious in the following ways:

They threaten the viability of our discipline: Social science already faces a public perception problem. Yet the troubled research discussed here targets the very people who are the most skeptical portraying them as racist (and often sexist, irrational and ignorant as well) on flimsy evidentiary grounds. Yet the people being maligned in this research also happen to control the purse strings for federal research funding, state funding for education, etc. (al-Gharbi 2017c). Their pundits already argue that social research is shoddy leftist propaganda, scarcely worth serious engagement or attempted implementation. The works discussed here provide 'smoking guns' to charges of bias. This is a dangerous state of affairs.

Cascade effects and feedback loops: When prominent and respected scholars publish flawed research, it can pollute understanding of a subject matter in a way that becomes very difficult to correct. Consider all the emerging scholars who have been assigned Hochschild or Coates' recent works as a means for understanding Trump's election. Consider all of the subsequent research that will invariably reference and attempt to build on these works, and the impact that this next generation of research will have in turn, ad infinitum. In other words, the stakes of research about the last election extend well beyond the 2018 or 2020 races - myopic political scholarship can lead astray future activists and scholars in their own quests to understand and address social problems.

Researchers can also help reify unfortunate social phenomena (Stampnitzky 2013, Watters 2011). In this instance, unfairly labelling Trump voters as bigots -- simply because they voted for the Republican in $2016-$ 
this will likely stir up resentment against those who seem to be promulgating the charge (academics, journalists and activists - especially minorities). Voters may double-down on their support for Trump, when they might otherwise defect, simply in order to 'stick it' to those disparaging them (al-Gharbi 2015b). They may even come to believe, on the basis of experts' ubiquitous racialized narratives, that Trump is the best candidate to promote white voters' interests (Gray 2018) - despite whatever problems they may have with what he has said or done so far. In other words, by demonizing Trump supporters as racist, social researchers may be laying the groundwork for the very negative externalities they wish to avoid (i.e. Trump's reelection, increased resentment against the media, the academy, minorities, etc.).

In fact, one bitter irony of allowing research to be distorted by political aspirations is that the unreliability of the resultant scholarship can undermine those very aspirations. In this instance, it is critical for 'the resistance' to have an accurate understanding of who voted for Trump and why: inaccurate research would likely generate ineffective electoral strategies. Indeed, motivated research and confirmation bias likely explain why most analysts couldn't see Trump's strength in the last cycle (al-Gharbi 2017a). If progressive scholars wish to avoid another humiliating and costly 'black swan' defeat for their party in 2020 , then we'll need to begin with a sober reckoning of how he won in the first place -- even if this means being more charitable towards Trump voters than we feel naturally inclined to be, or being skeptical of claims that would be very satisfying to accept.

Finally, it is normatively dangerous to countenance problematic research because it edifies our identities. If scholars are sincerely worried about the way 'Trumpism' erodes and debases norms and institutions we hold dear, we cannot effectively fight these trends by ourselves undermining the methodological, evidentiary and disciplinary standards of our chosen professions. We should instead try to defend and embody our values all the more, and to exemplify our best-practices - especially with research relating to Trump and his supporters.

\section{APPENDIX I:}

\section{John Sides, “Race Religion and Immigration in 2016," Voter Study Group, June 2017.}

In September 2017, prior to publication of the original version of this essay, I reached out to the editors of the Monkey Cage (Washington Post) and expressed my concerns about the glaring problems in Wood's piece. They declined to issue a correction or retraction, nor to permit a rejoinder. Moreover, they emphasized that even if Wood's essay was flawed, his basic claim (Trump voters were motivated largely by racism) was nonetheless correct - as evidenced by the wide literature of work in the field which comes to similar conclusion without suffering the shortcomings I highlighted. To underscore this point they sent along an essay by Vanderbilt political scientist John Sides (who also happens to be the publisher of the Monkey Cage). Unfortunately, rather than ameliorating my concerns about the "Trump studies" literature, the essay serves as yet another prime example of how the enterprise frequently goes awry.

Like Wood and Coates, Sides begins his research from the premise that because Trump repeatedly used inflammatory language about minority and immigrant groups throughout the campaign, and subsequently won the lion's share of the white vote, these whites must have voted for Trump because of his racialized rhetoric. His study purportedly demonstrates "cultural anxiety" to be the most explanatory factor in explaining why white Americans voted for Trump over Clinton. ${ }^{30}$ The proof offered for this claim was that Voter Survey Group respondents' attitudes toward immigration, blacks and Muslims better predicted whether a participant voted Democrat or Republican in 2016 than they did in 2012. Figure 5 visualizes this data.

al-Gharbi, Musa (2018). "Race and the Race for the White House: On Social Research in the Age of Trump."

The American Sociologist (49)4: 496-519.

p. 16 


\section{The Relationship between 2011 Attitudes and Vote Choices in 2012}
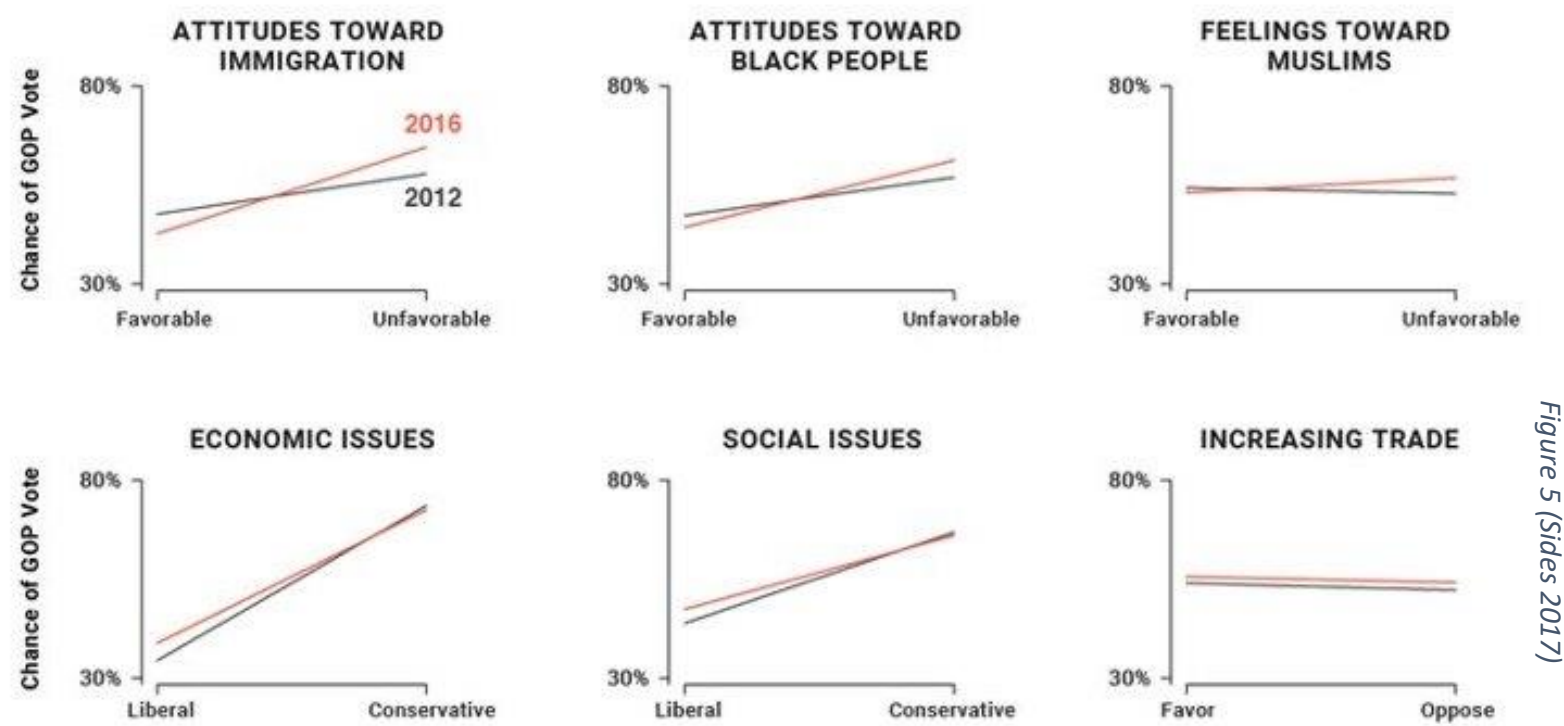

IMPORTANCE OF ENTITLEMENT PROGRAMS

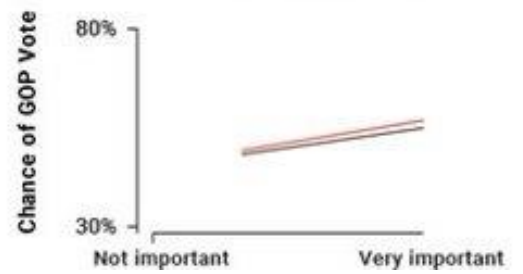

STATE OF ECONOMY

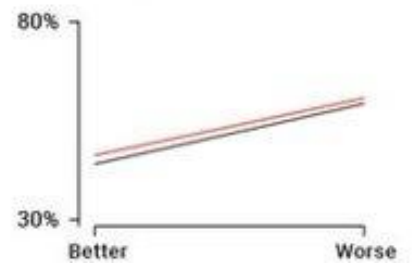

PARTY IDENTIFICATION

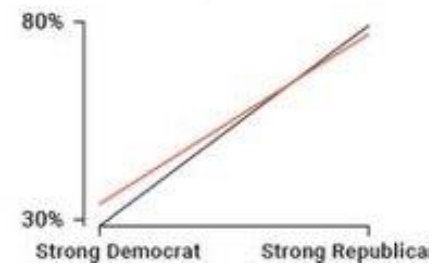

What becomes immediately apparent in the chart is that while white respondents' 2011 attitudes about immigrants, blacks and Muslims may been more predictive of a GOP vote in 2016 than they were in the last cycle, ${ }^{31}$ "economic issues," "social issues" and "party identification" remained far more reliable indicators of a vote for Trump than any of the "cultural anxiety" factors. In other words, the best bet for figuring out whether a white voter supported Trump would not be to look at their attitudes towards immigrants, blacks or Muslims, but instead to check their position on economic or social issues - or for that matter, just looking at which political party they identify with. Indeed, by Sides own reckoning, roughly 89\% of those who supported Romney in 2012 also voted for Trump in 2016 (Figure 6). 


\begin{tabular}{l|c|ccc}
\multicolumn{1}{c|}{$\begin{array}{c}\text { voTE CHOICE } \\
\text { IN 2016 }\end{array}$} & $\begin{array}{c}\text { PERCENT } \\
\text { IN SAMPLE }\end{array}$ & Barack Obama & $\begin{array}{c}\text { voTE CHOICE IN 2012 } \\
\text { Mitt Romney }\end{array}$ & Other Candidate \\
\hline Hillary Clinton & $47.3 \%$ & $86.4 \%$ & $5.4 \%$ & $26.0 \%$ \\
Donald Trump & $46.2 \%$ & 9.2 & 88.6 & 38.9 \\
Gary Johnson & $3.1 \%$ & 1.5 & 3.0 & 21.9 \\
Jill Stein & $1.2 \%$ & 1.7 & 0.1 & 7.6 \\
Evan McMullin & $0.3 \%$ & 0.01 & 0.5 & 0.3 \\
Other candidate & $2.0 \%$ & 1.3 & 2.3 & 5.4 \\
& $100 \%$ & $100 \%$ & $100 \%$ & $100 \%$ \\
\hline
\end{tabular}

Note: Unweighted $\mathrm{N}=7,156$

Therefore, it seems problematic to assume that the apparent change in the significance of 'cultural' issues from 2012 to 2016 was a decisive factor for most Trump voters - who would not have been inclined to vote Democrat irrespective of Trump's rhetoric ${ }^{32}$ - and indeed, regardless of who the Republican nominee was. Had Jeb Bush, Marco Rubio or Ted Cruz won the nomination, they would have voted for them instead, just as they had voted for Mitt Romney in the previous round, and likely John McCain and George W. Bush in the cycles before. Indeed, previous research shows that Democrats had been suffering significant attrition - not only with whites, but among all racial groups - in every midterm and general election for the better part of a decade. That is, what happened in 2016 seems like the culmination of a longrunning and broad-based trend of eroding Democratic popular support (al-Gharbi 2017b).

Given this pattern of broad-based erosion of Democratic vote share among all racial groups -- and consistent gain among Republicans post 2008 -- it is perplexing that Sides chose to focus exclusively on whites for the longitudinal component of the study. As we have previously explored, given that white turnout was stagnant, and that Trump got a smaller share of the white vote than his immediate predecessor - but outperformed Romney with Asians, Blacks and Hispanics -- it is likely that switches among people of color helped turn the election in Trump's favor. Defections among African Americans in states like Michigan, Pennsylvania or Ohio - or among Latino voters in states like Florida - likely played a pivotal role in 'flipping' those states and, consequently, allowing Trump to win the Electoral College. That is, if the goal was to understand why the election turned out the way it did, it is likely just as important, perhaps more important, to understand minority Trump voters in addition to whites. It seems clear from the report that data for these voters was also readily available to Sides. Yet, these constituents were analytically erased prior to the regressions even being run. They were not included in depicting the general trends, nor were minority Trump voters compared or contrasted to white Trump voters.

Of course, including these respondents would have significantly complicated the narrative the author seemed committed to telling about the role of race and racism in the 2016 cycle. Acknowledging Trump voters of color, and highlighting the electoral significance of these voters, would have made it very difficult to spin a clean story about Trump winning as a result of ethnic nationalism - especially if it turned out that these constituents (minorities who voted for the Republican candidate in 2016) exhibited comparable trends in their levels of 'cultural anxiety' as compared to their white peers. Consciously or unconsciously, these realities may have played a role in the curious decisions that were made with respect to study design. 
There is also a more general problem Sides' data point to, but which he fails to adequately account for (along with many, many other scholars who do work in this genre): analyses that are focused on Trump and his rhetoric in order to explain why people voted Republican in 2016 miss the reality that the overwhelming majority of these voters were going to vote -- and vote Republican -- almost regardless of who was on the top of their ticket (or at the top of the Democratic ticket), and irrespective of "cultural anxiety" levels at any specific point in time, etc. These votes do not need to be explained, and cannot be well-explained, by appeals to the idiosyncrasies of the 2016 cycle and its candidates. The votes that actually do need to be explained are those from irregular voters who chose to participate in this cycle, regular voters who chose to sit the election out, and those who voted Democrat in the last cycle(s) but for the Republican in this cycle (and vice-versa). These 'non-constant' voters are the ones who can be most naturally described as 'deciding' an election. They are also the ones whose voting behavior would have been most determined by the specific features of the candidates under consideration and the idiosyncrasies of that particular election cycle. In other words, most of the data in Figure 5 is actually "noise" with respect to understanding the electoral outcome. One cannot explain variation by appeal to a constant. Consequently, if one wants to understand the impact of factors that changed from one cycle to another, leading to a different electoral outcome in one cycle as compared to the next, one should focus on the voters whose behaviors actually changed across cycles.

\section{APPENDIX II:}

\section{Diana Mutz, "Status Threat, Not Economic Hardship, Explains the 2016 Presidential Vote." Proceedings of the National Academy of Sciences 115(19): E4330- 9.}

Had Diana Mutz's paper been published prior to the original version of this study, it would have been one of the core cases discussed. The essay was published in a flagship journal. It has been highly influential, already cited at least 266 times to date (Google Scholar). It received glowing coverage in the New York Times, Economist, The Atlantic, Slate, CNN, Pacific Standard and many other outlets (Chokshi 2018; V.V.B. 2018; Khazan 2018; Chotiner 2018; Waldow 2018; Jacobs 2018) - often held up as definitive proof that Trump's election was a last-ditch effort by whites to preserve their eroding privilege. It is also a paper that contains several fatal errors that somehow went unnoticed by the author, the journal reviewers and editors, and the myriad journalists covering the research. Indeed, as will be demonstrated, Mutz's data seem to be diametrically opposed to the narrative she spins (a narrative spun, ostensibly, on the basis of said data).

The paper features two studies that will be discussed here. ${ }^{33}$ The first, and the main contribution, is a nationally-representative panel study looking at identical questions asked of the same voters in October 2012 and 2016. In principle, this is a fantastic approach. Again, fancy analyses are generally not required to explain why committed partisans vote along party lines in any particular race. Far more pertinent to the outcome of most races, more in need of explanation -- and the votes that likely are determined by the idiosyncrasies of particular cycles -- are those whose voting behavior changed from one election to the next. By focusing on a subset of these constituents (namely those who switched from Obama to Trump), Mutz's study is a breath of fresh air. In many other respects, less so:

Similar to other works in the "Trump studies" genre, Mutz's description of "status threat" and its role in motivating support for Trump is heavily racialized. As with most others in the genre, the narrative she is trying to spin seems to be prima facia confounded by the available data on racial voting patterns: 
turnout among whites was roughly stagnant relative to 2012 -- and Trump got a lower share of the white vote than Mitt Romney. He was able to eke out a win because Hispanic and Asian turnout was higher than in previous cycles, and Trump won a larger share of these groups -- and African Americans -- than his predecessor did. That is, some of the most critical switchers in this cycle (perhaps the most critical defectors) were non-whites. Were the millions of minority voters who cast their ballots for Trump also driven by "status threat?" Mutz doesn't really speak to this phenomenon at all. Her discussion is almost entirely about whites - as is much of the public discussion about the paper -- yet Mutz apparently failed to control for race in her panel study (see Table 1/ S1). This is a big problem, which we'll return to later. However, the core defect in Mutz's approach is that she is purporting to rule out economic considerations as a driver of Trump support, yet the variables she relies upon to measure "status threat" are almost purely economic in nature. Worse, the author makes glaring errors in interpreting that data.

\section{Status Threat?}

For the panel study, Mutz measures "status threat" primarily in terms of responses to questions about trade, China and immigration. Here is the question on trade used in the panel study:

"Some people think that the United States should have more trade agreements with other countries. Others believe that the United States should have fewer trade agreements. Of course, some other people have opinions somewhere in between. Where would you place yourself on this scale, or have you not thought much about this?" (seven-point scale from fewer to more).

This is a purely economic question, with nothing asked or even suggested about any other topic (such as America's relative standing in the world). Mutz's data show that voters grew more skeptical towards trade agreements between 2012 and 2016 (Table S1), especially those who voted for Trump. However, voters perceived a greater distance between themselves and both candidates in the 2016 cycle, as compared to the candidate options in 2012. Even validated 2016 Republican voters reported greater distance between themselves and Trump relative to their candidate in the previous cycle (Mitt Romney, who was a strong supporter of international trade). Indeed, Table S2 shows that Trump's views on trade rendered respondents nearly 5\% more likely to vote against him than they otherwise would have been. Had his opponent struck a non-alienating position on this issue, trade would have been a losing issue for the Republican candidate. However, there was an even larger growth in the perceived distance between voters and Hillary Clinton. Perceived distance between voters and the Democratic candidate rendered respondents 9\% more likely to vote for the Republican candidate than they otherwise would have been. That is, both candidates seemed to strike unpopular positions on trade - Clinton's just happened to be marginally less desirable than Trump's (resulting in a net $4.8 \%$ increase in likelihood of voting for Trump on the basis of this particular issue).

With regards to China, there is nothing in the panel survey question that speaks about "America's place in the world" or any other measure of relative standing at all. However, there is a good deal of focus on economic concerns (emphasis added):

"There are different views about China. Some people see China as more of an opportunity for new markets and economic investment, while others see it as a threat to our jobs and security. Still others are somewhere in between. Which view is closer to your own?" (seven-point scale from threat to opportunity).

al-Gharbi, Musa (2018). "Race and the Race for the White House: On Social Research in the Age of Trump."

The American Sociologist (49)4: 496-519.

p. 20 
More troubling for Mutz is that public attitudes on this question did not change in a statistically significant way across the panel waves (Table S1). If this was a variable that adequately measured "status threat," and if there was indeed an increase in perceptions of "status threat" (as Mutz argues), then we would expect to see changes in public attitudes on this issue. At the very least, this should show with respect to those who voted for Trump. And yet, this is not borne out in her data at all. There was no significant change in opinions on China - suggesting that either (1) there was no increase in "status threat" between 2012 and 2016, (2) this is a poor variable for measuring the purported increase in "status threat," or (3) some combination of both of these.

What changed between 2012 and 2016 was not voters' opinions on this topic, but the perceived distance between voters and various candidates on this issue. That is, voters' positions were roughly the same, but the candidates' rhetoric and positions were not. On average, validated Republican voters felt that their candidate was a little closer to their (preexisting) position on China as compared to last cycle reflected in the negative coefficient for 'distance' on this question (-0.017 on a seven-point scale). However, for most voters - including Democrats -- there was no statistically significant relationship change in either direction relative to the Republican candidate. As with trade, the real story in the data is that a significant rift that opened in the perceived distance between voters and the Democratic candidate between 2012 and 2016. To the extent that China mattered, it wasn't because voters supported Trump's position on China, so much as they disagreed with Clinton's. Table S2 shows that proximity to Trump on China had a negligible impact on vote preferences (rendering voters less than $2 / 10$ of $1 \%$ more likely to vote Republican than they otherwise would have been). Meanwhile, distance from Clinton on China made people $2 \%$ more likely to vote Trump (an effect ten times as large).

In short, what we see on China and trade is that Obama-Trump switching seems to have been motivated much more by aversion to Hillary Clinton and her positions than support for Trump and his platform. It is a negative partisanship story more than a status threat story - especially given that neither the questions on trade nor on China said anything at all about race, America's relative standing, etc. However, it is Mutz's treatment of the immigration variable that is perhaps the most telling:

On its face, immigration may seem like the strongest "issue" variable Mutz relies on for measuring "status threat" in the panel study; it is the only one that fails to evoke obvious endogeneity concerns in the framing of the question itself (with respect to theory she is trying to rule out, economic factors):

"On immigration, some people argue that US policy should focus on (returning illegal immigrants to their native countries/creating a pathway to US citizenship for illegal immigrants). Other people argue that US policy should focus on (creating a pathway to US citizenship for illegal immigrants/ returning illegal immigrants to their native countries). Still others are somewhere in between. Where would you place yourself on this scale, or have you not thought much about this?" (seven-point scale from anti- to pro-immigration).

However, this does not mean there is no reason to be concerned about endogeneity here. Indeed, Mutz herself acknowledges that opposition to immigration often seems to be driven primarily by economic concerns rather than status threat (emphasis added):

"To the extent that immigration is perceived as threatening by Americans, scholars find that it is due to the increased economic burden Americans believe immigrants place on the social welfare system rather than a threat to white status (35). Nonetheless, it remains possible that the heightened salience of immigration contributed to Trump's victory..."

al-Gharbi, Musa (2018). "Race and the Race for the White House: On Social Research in the Age of Trump."

The American Sociologist (49)4: 496-519.

p. 21 
In fact, Mutz's data point the opposite direction. Table S1 shows that all voters grew warmer on immigration from 2012- 2016 - including validated Republican voters. That is, Trump voters were, on average, more supportive of immigration than Romney voters. Voters did not perceive any change in distance between themselves and Hillary Clinton on this issue (as compared to the previous Democratic candidate). However, there was a great increase in perceived distance between voters and the Republican candidate. Even validated Republican voters were merely ambivalent with respect to Trump, there is no increase in affinity with their candidate on this issue as compared to the last cycle, nor was there increased antipathy towards Democrats' posture on immigration.

Table S1. Mean change over time in key independent variables among self-reported and validated voters, 2012-2016 panel

\begin{tabular}{|c|c|c|c|c|c|}
\hline Change in & $\begin{array}{l}\text { Change among all } \\
\text { self-reported voters }\end{array}$ & $\begin{array}{l}\text { Change among } \\
\text { validated voters }\end{array}$ & $\begin{array}{c}\text { Change among } \\
\text { validated } \\
\text { Republicans }\end{array}$ & $\begin{array}{l}\text { Change among } \\
\text { validated } \\
\text { Democrats }\end{array}$ & Scale \\
\hline Party identification (Democrat) & $-0.04 *$ & $-0.04^{*}$ & 0.02 & -0.01 & $1-3$ \\
\hline \multicolumn{6}{|l|}{ Personal economic hardship } \\
\hline Household income & $0.28^{* * *}$ & $0.28^{* * *}$ & $0.43^{* *}$ & $0.26^{*}$ & $1-21$ \\
\hline Looking for work & $-0.02^{* *}$ & $-0.02^{* *}$ & -0.02 & $-0.03^{*}$ & $0-1$ \\
\hline Personal financial situation (better) & $0.11^{* * *}$ & $0.08^{*}$ & $0.21^{* * *}$ & -0.03 & $1-5$ \\
\hline On trade & $-0.32^{* * *}$ & $-0.34^{* * *}$ & $-0.80^{* * *}$ & 0.08 & $1-7$ \\
\hline On immigration & $0.35^{* * *}$ & $0.40^{* * *}$ & $0.29^{* *}$ & $0.55^{* * *}$ & $1-7$ \\
\hline On China & -0.03 & -0.01 & -0.09 & 0.04 & $1-7$ \\
\hline \multicolumn{6}{|l|}{$\begin{array}{l}\text { Perceived distance of } \\
\quad \text { Democratic candidate on }\end{array}$} \\
\hline On trade & $0.69^{* * *}$ & $0.72^{* * *}$ & $1.05^{* * *}$ & $0.37^{* * *}$ & $0-6$ \\
\hline On trade & $0.34^{* * *}$ & $0.40^{* * *}$ & $0.22^{* *}$ & $0.60^{* * *}$ & $0-6$ \\
\hline On immigration & $0.42^{* * *}$ & $0.51^{* * *}$ & 0.19 & $0.76^{* * *}$ & $0-6$ \\
\hline On China & -0.05 & -0.02 & $-0.17^{*}$ & 0.17 & $0-6$ \\
\hline SDO & $0.16^{* *}$ & $0.16^{*}$ & $0.34^{* * *}$ & 0.02 & $1-10$ \\
\hline National economy & $0.08^{* *}$ & $0.09^{* *}$ & $0.24^{* * *}$ & 0.01 & $1-5$ \\
\hline
\end{tabular}

Note that economic variables are coded so that improvement is the higher score, and looking for work is a dummy variable, indicating if the respondent is currently looking for work. Own issue opinions are coded so that high scores indicate protrade, proimmigration, pro-China. Increasing levels of SDO have positive scores. ${ }^{*} P<0.05$; ${ }^{* *} P<0.01$; ${ }^{* *} P<0.001$.

Again, if immigration was an adequate measure of "status threat" and voters were in fact more threatened in 2016 than in the previous cycle, we would expect to see increased opposition to immigration - at least among those who voted for Trump. Instead, we see literally the opposite of this. For two of Mutz's core "status threat" variables, then, we saw either no change in attitudes, or a change in attitudes that would indicate decreased threat (on Mutz's model). Given that these are fully half of the variables she uses to gauge "status threat," it seems clear that either (1) there was no increase in "status threat," (2) her model was poorly specified, or (3) some combination of these factors. This should have been a stopping point for those who reviewed the paper. Given that she indisputably has a poorly constructed model and/or is incorrect in her claims about heightened status threat, whatever else that follows is sure to be on shaky empirical ground. However, given that the paper was ultimately accepted for publication nonetheless, we will continue our exploration as well: 
Table S2 shows that perceived distance from the Democratic candidate on immigration rendered voters roughly $1 / 10$ of $1 \%$ more likely to vote for Trump. Meanwhile, perceived distance from the Republican candidate rendered voters roughly 5\% more likely to vote for Hillary Clinton. That is, the effect of being distant from Trump was much stronger (more than 40x stronger) in driving voters towards Clinton than distance from Clinton was at driving voters to Trump.

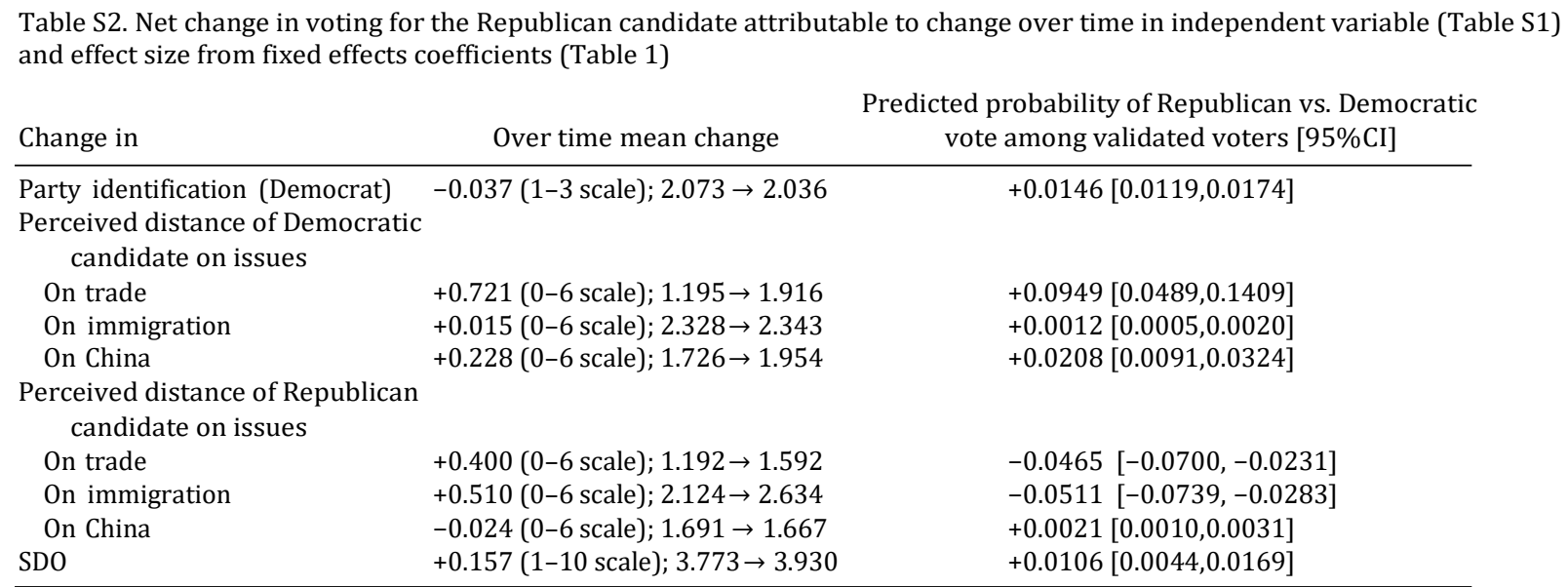

Calculations are based on the fixed effects model for vote choice among validated voters (Table 1) using the mean change of the central variable over time (Table S1) to calculate the difference in the predicted probabilities of Republican vote choice. Entries in column 2 represent the change over time from wave 0 to wave 1 . Column 3 shows the changes in the predicted probability of voting for the Republican presidential candidate based on change in one variable at a time, with positive changes indicating shifts toward more Republican votes and negative change indicating shifts toward Democratic votes. All other variables are held at their wave 0 means. Fig. 2 summarizes the net effect of major changes on Republicanvs. Democratic voting.

Put another way: Mutz's data strongly suggests that immigration was, on balance, a losing issue for Republicans in 2016; it rendered people less inclined to switch over to Trump from Obama than they otherwise would have been. This is a major finding of Mutz's study, and an important contribution for understanding the dynamics of the 2016 race and beyond. It suggests that Trump won despite rather than because of his positions on immigration. Yet, like Wood, Mutz ultimately argued in direct opposition to her own data in order to advance a particular narrative on the role of race in the 2016 election.

\section{Economic Hardship v. Economic Anxiety}

Table S1 shows that between 2012 and 2016, on average Americans reported higher household incomes, a better personal financial situation, were marginally less likely to be looking for work, and held a slightly more positive view on the state of the national economy. Indeed, validated Republican voters saw even larger gains than most in terms of household incomes, rated their personal financial situations -- and the current state of the national economy -- even higher than most others. Hence, Mutz argues, economic hardship seems like an implausible explanation for Trump support. However, these findings do not rule out economic anxiety as a driver of support for Trump. After all, increases in wealth do not necessarily translate into increased emotional well-being (Kahneman \& Deaton 2010). Indeed, one can have decreasing economic hardship and increasing economic anxiety. This is a common phenomenon, especially among people in emerging economies (Easterlin 2005, Easterlin et al. 2012) and the relatively well-off in America (Reeves 2017, Luthar 2003, Day 2017, Sherman 2017). 
This helps explain, for instance, why people often tend to grow more economically conservative as their socioeconomic position increases (Bartels \& Cramer 2018).

Economic anxiety can take the form of personal fears about the security of the particular job one currently holds, but it can also take the form of anxiety about broader economic trends, the perceived health and stability of the national economy, the feasibility of being able to maintain one's social position, etc. ${ }^{34}$ Mutz's panel data seem highly consistent with economic anxiety being a possible driver of support for Trump. For instance, Table S3 shows that positive feelings about the personal effects of trade, increased area median income by wave, and positive evaluations of the national economy were all inversely correlated with warmth towards Trump. In other words, the better respondents felt about the effects of trade or the state of the economy, or the higher their median income of their area was, the worse they felt about Trump. Conversely, then, to the extent that someone was living in an area that saw declines in median income from 2012-16, felt they were personally harmed by trade, or held a less-rosy view about the state of the national economy - they were likely to feel more warmly about Trump. Pessimism about the national economy is strongly correlated with warmth towards Trump and voting for Trump. This is all highly consistent with an "economic anxiety" story. And yet Mutz attempts to argue, on the basis of this very data, that economic concerns were not a major factor in 2016.

Table S3. Economic predictors of Republican candidate support: fixed effects panel analysis, 2012-2016

\begin{tabular}{|c|c|c|c|c|}
\hline \multirow[b]{3}{*}{ Change in } & \multicolumn{4}{|c|}{ Republican Thermometer } \\
\hline & \multicolumn{2}{|c|}{ Advantage } & \multicolumn{2}{|c|}{ Republican/Democrat vot } \\
\hline & Coefficient & $t$ Value & Coefficient & $z$ Value \\
\hline Party identification (Democrat) & -1.097 & $-5.440 * * *$ & -2.199 & $-14.665^{* * *}$ \\
\hline \multicolumn{5}{|l|}{ Personal economic hardship } \\
\hline Household income & -0.010 & -0.250 & -0.004 & -0.120 \\
\hline Looking for work & -0.568 & -1.250 & -0.719 & -0.902 \\
\hline Personal financial situation (better) & 0.057 & 0.480 & -0.077 & -0.481 \\
\hline Personal effects of trade (better) & -0.282 & $-2.810 * *$ & -0.042 & -0.256 \\
\hline \multicolumn{5}{|l|}{ Immediate economic context } \\
\hline Area unemployment $\times$ wave & -0.072 & -1.240 & -0.097 & -0.879 \\
\hline Area percentage manufacturing $\times$ wave & 0.019 & 1.040 & -0.011 & -0.353 \\
\hline Area median income $\times$ wave & -0.017 & $-3.090 * *$ & -0.005 & -0.631 \\
\hline National economy & -0.833 & $-7.600 * * *$ & -1.173 & $-7.930 * * *$ \\
\hline Wave (2012-2016) & 0.793 & 1.300 & 0.858 & 0.819 \\
\hline Constant & 15.180 & $21.510 * * *$ & 8.015 & $10.651 * * *$ \\
\hline Sample size & 1,194 & & 891 & \\
\hline
\end{tabular}

For analysis of Republican thermometer advantage, sigma_u $=4.04$; sigma_e $=2.57$; and rho $=0.71$. Fixed effects ordinary least squares regression was used to analyze change in Republican thermometer advantage; fixed effects logit regression was used to analyze Republican versus Democratic vote. ${ }^{* *} P<0.01,{ }^{* * *} P<0.001$.

\section{Social Dominance Orientation}

In Mutz's argument, the major variable that was supposed to help tie the "issue" variables to some notion of "status threat" was the alleged "social dominance orientation" (SDO) of Trump voters. ${ }^{35}$ 
One straightforward concern about the use of this construct is that, insofar as it primarily measures (in)egalitarian commitments, it is somewhat easy to confound with conservativism/ progressivism (Reyna 2017). These concerns are heightened here because Mutz declined to control for ideological selfidentification in either study (the panel or the cross-sectional) - relying exclusively on Party ID.

However, Party ID and ideological leanings are not simply substitutable. For instance, African Americans and Hispanics vote solidly Democrat (roughly 9:1 and 2: 1 respectively, as compared to whites, who trend Republican), yet they nonetheless tend to be more socially conservative and religious than whites on average, and are much less likely to self-identify as "liberal" (al-Gharbi 2019a). Perhaps most concerning here, African Americans are often far more skeptical than other Democratic constituents towards immigration (Bouie 2013) - one of Mutz's key "status threat" variables. This ties back to (exacerbates) the problem that Mutz did not control for race in the panel study. We are left with two concerns at the outset then: (1) given how small the SDO effect is in her regressions, it seems unlikely that there would have been any observed SDO effect had Mutz controlled for ideology in addition to (or instead of) Party ID and (2) although Mutz is trying to tell a story about whites, the observed effects vis a vis SDO are likely driven in large part by minority voters as well - given that Mutz failed to control for race in the panel study, and because minority voters are more likely to hold socially conservative views than whites, on average.

More broadly, a narrative of Trump voters as inclined towards dominance seems misleading, given that their average SDO score was 3.93 on a 10-point scale. It seems more consistent with the data to emphasize that Trump voters are pretty egalitarian overall -- albeit perhaps marginally less so than Clinton voters - rather than defining Trump voters as dominance-oriented. Indeed, the average change in SDO between 2012 and 2016 among validated Republican voters was 0.34 points on a 10-point scale; this is hardly a sea change. Nor did it have a major impact. By Mutz's own estimates (Table S2), the increase in SDO among voters from 2012 to 2016 corresponded to a roughly $1.1 \%$ increase in likelihood to vote for Trump. For comparison, identifying as a Democrat had a larger effect (1.5\% increase) on rendering someone more likely to vote Trump than the change in SDO. The effect of the change in SDO was countervailed several times over by the net effects of immigration (which, again, rendered voters $4.99 \%$ more likely to vote against Trump than they otherwise would have been). In short, Mutz seems to be trying to get a lot of rhetorical mileage out of a very small effect, even bracketing the aforementioned concerns about what the increase in SDO actually means.

However, not only is the actual increase in SDO borderline trivial and possibly confounded with ideological leanings, the argument in this key section of the paper (circa notes 45-49), actually rests upon a logical fallacy. Mutz argues:

1. When people feel threatened, we often see an increase in SDO

2. We observe an increase in SDO

$\therefore$ Voters must have felt an increased threat. ${ }^{36}$

This is called 'affirming the consequent.' Logically speaking, we cannot legitimately infer heightened perception of threat from an observed increase in SDO. ${ }^{37}$ And without the ability to make this move, there is basically no reason to associate any of attitudinal shifts observed in the panel study with "status threat" - especially given that most of these questions were, again, almost purely economic in nature.

al-Gharbi, Musa (2018). "Race and the Race for the White House: On Social Research in the Age of Trump."

The American Sociologist (49)4: 496-519.

p. 25 
Put another way, given the economic nature of all of the "issue" variables, the fact that most of the “issue" variables did not trend in the direction Mutz's model would suggest, the identified errors in Mutz's interpretations of those variables, and the deep problems with her SDO scale and the logic underpinning its use - the panel study does not seem to provide any kind of meaningful evidence that Trump voters were motivated by "status threat." Worse, the panel study does provide compelling evidence that Trump voters were strongly motivated by economic issues - and not just with respect to trade and China: increased pessimism about the economy, feeling harmed by trade, or living in an area that saw declines in median income - all of these were strongly correlated with increased warmth towards Trump (again, Table S3). Across the board, what seemed to matter more was not affinity with Trump, but antipathy towards Hillary Clinton on the issues - the one exception being immigration, which was a losing issue for Trump. Again, Mutz's narrative is almost diametrically opposed to her own data.

Of course, the panel study was just one half of her paper, albeit the most novel and significant contribution. There is also a cross-sectional study, looking at a wider range of predictors, focused specifically on 2016. Unfortunately, it does little to ameliorate the concerns here:

\section{The Cross-Sectional Study}

For the cross-sectional study, the questions about trade and immigration were roughly equivalent to the panel study; the prompts on trade and China were economic in nature, and none of the questions, to include the questions on immigration, indicated anything about race or relative status. ${ }^{38}$ Accordingly, given the preceding analysis of those variables, we can set them aside here; they do not tell us anything about "status threat." Social Dominance Orientation (SDO) was weakly associated both with warmth towards Trump, and voting for Trump over Clinton - although this relationship skated on the margin of statistical significance.

With respect to the new "status threat" variables Mutz introduces, perceptions about U.S. superiority and concerns about terrorism had no statistically significant relationship with warmth towards Trump, nor voting preferences, nor voting behavior. A perception that the American way of life was threatened had no relationship to voters' feelings about Trump and was only weakly correlated with voting preferences or voting behavior. "Support for Isolationism" was more strongly related with warmth towards Trump. However, Mutz provides no explanation within the supplementary materials or the paper about what this construct means, specifically, nor why it is coded as a measure of "status threat." Prima facie it seems more likely that a concern for preserving or enhancing America's status in the world would drive support for global interventions against perceived rivals or threats (i.e. isolationism would be inversely correlated with "status threat"). Indeed, many foreign policy hawks explicitly argue for military action by appealing to the decline in America's global standing, etc. But we can actually set this question aside, as there is no statistically-significant relationship between "support for isolationism" and vote preference or voting behavior.

The only new "status threat" variable that shows any kind of robust and consistent statistical significance is "perceived discrimination against high-status groups (whites, men, Christians)." It is to this composite variable that we now turn. The first thing to note is that there does not seem to be any meaningful relationship between evaluations of relative discrimination of high v. low status groups and antipathy towards low-status groups.

al-Gharbi, Musa (2018). "Race and the Race for the White House: On Social Research in the Age of Trump."

The American Sociologist (49)4: 496-519.

p. 26 
Although "perceived discrimination against high-status groups" is statistically significant across the board, "domestic prejudice" is only weakly correlated with vote preference and has no apparent relationship with warmth towards Trump nor voting behavior. The second thing to note is that it is difficult to interpret the coefficients on this construct. As Matt Grossman (2018b) aptly put it (emphasis added):

\footnotetext{
"Studies finding influential perceptions of white or male discrimination are actually based on relative comparisons with disadvantaged groups. Scholars have a tendency to imply that the liberal ends of these scales are normal and look for deviation from them, such as by measuring "denial of discrimination." But one could equivalently restate common findings in the other direction. People who reflexively believe claims of discrimination because they perceive structural barriers for disadvantaged groups were more likely to support Hillary Clinton... The liberal side of the scales may also represent biased thinking. Liberals perceive more racism and sexism than racial minorities and women say they experience. Experiments show that liberals perceive tests where men or whites perform better as less credible than equivalent tests showing women or minorities doing better, even though conservatives rate them equally credible. Liberals are thus predisposed to believe discrimination is the cause of disadvantaged group disparities. Seeing these attitudes as more than simple bias may help understand Trump support across genders and races."
}

Indeed, the apparent correlation between vote preference and the "perceived discrimination against high groups > low-status groups" ratio could actually be in large part a product of Clinton voters holding extremely 'woke' views rather than Trump voters denying discrimination against low-status groups or perceiving great discrimination against high-status groups.

There are reasons to believe this may in fact be a major factor in Mutz's result. Recall Wood's study: Republicans grew more sympathetic towards discrimination against minorities in 2016, just as they have grown more supportive of immigration in Mutz's own data. However, Democrats expressed unprecedented levels of concern about prejudice and discrimination in 2016, driving the entire apparent divergence between partisan attitudes on race. The radical shift on racial attitudes among Democrats, captured in Wood's data, apparently began circa 2014 and has continued since Trump's election -- to the point where liberal whites are now significantly more "woke" on racial issues than the typical black or Hispanic (Kaufmann 2019, Yglesias 2019). Consequently, without baselines for the average Trump and Clinton voter on the various components of the perceived discrimination scale, it is unclear which party is driving the effect in Mutz's data (nor how). The ratio could be a product of extraordinarily high-perceived discrimination against whites, men and Christians (and/or low perceived discrimination against minorities) among Trump voters - or it could be a product of extraordinarily high perceived discrimination against minorities (paired with a denial of any discrimination against whites, men or Christians) among Clinton voters. Or it could be a function of both. In any case, this construct does not cleanly indicate what Mutz wants to argue. 
Table S4. Cross-sectional analysis of predictors of Trump support, 2016

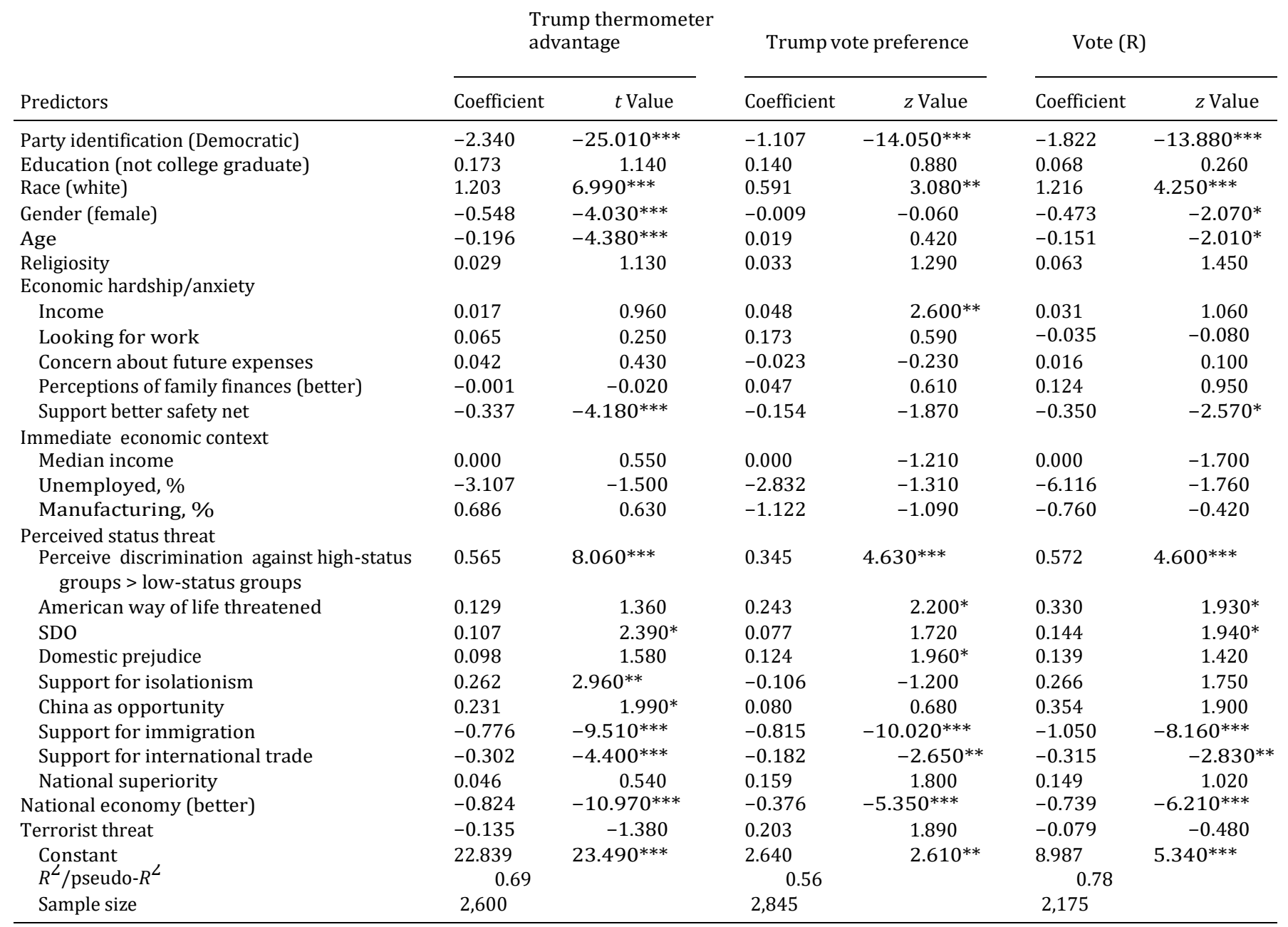

Data were collected by Amerispeak/NORC, October 2016. All variables are described in detail in Cross-Sectional Survey. Trump thermometer rating is on a 20- point scale. Trump vote preference is dichotomous, indicating support for Trump (one) or anyone else (zero). Trump/Clinton vote is a dichotomous indicator of voting for Trump (one) or Clinton (zero), with third party voters eliminated. Trump thermometer advantage is analyzed using ordinary least squares regression. Trump vote preference and Trump/Clinton vote are analyzed using logit regression. ${ }^{*} P<0.05 ;{ }^{* *} P<0.01 ;{ }^{* *} P<0.001$.

As with the panel data, the cross-sectional study provides strong evidence that economic considerations were extremely salient in the 2016 election. Perceptions about the national economy seemed more impactful across the board than almost any other issue: the more pessimistic respondents were about the economy, the more they supported Trump. "Opposition to social safety nets" was also correlated with feeling warmth towards Trump and voting for him - although given the wording of the composite questions, ${ }^{39}$ the scale could also have been framed as "support for lowering taxes" - which would be more obviously resonant with the economic anxiety hypothesis than how Mutz chose to frame it (i.e. when people have more anxiety about the economy, they may wish to keep more of their income rather than allocating for use by the state). Also, had Mutz controlled for ideology in addition to (or instead of) Party ID, it is likely this effect would have been largely, or completely, washed out given that conservatives tend to generally be opposed to social safety nets. 
Opposition to trade - a question that was framed in purely economic terms -- is another major correlate with warmth towards Trump, vote preference and voting behavior. As previously discussed, Mutz herself concedes that immigration could be reasonably understood as an economic matter rather than indicating much about cultural anxiety or status threat.

Consequently, the cross-sectional does not demonstrate that "status threat" played a more significant role in shaping the 2016 electoral outcome than economic considerations did. If anything, the second study, like the first, suggests that economic issues were more significant than racial / cultural issues or questions of relative status; they were much more impactful than SDO, a belief in U.S. superiority, the perception that Americans' way of life was under threat, domestic prejudice, concerns about terrorism, etc.

\section{Conclusion}

Other sociologists have highlighted problems with Mutz's paper. For instance, Morgan (2018a) questioned some of her statistical modeling decisions. However, in focusing so intently on the "trees," such criticisms miss the "forest." It is not necessary to get into quibbles with Mutz over whether, for instance, a fixedeffects model is the right approach here. We can simply concede those design choices. Mutz's argument on SDO is premised on a logical fallacy. Her "status threat" variables are clearly endogenous to the explanation she is trying to rule out (economic considerations). They don't trend in the direction her model predicts in the panel study. In fact, her narrative in the paper stands in diametric opposition to her own data.

Diana Mutz is an excellent scholar; her work on cross-cutting networks is very important. ${ }^{40}$ It is frankly shocking that she would have produced such a low-quality work, apparently blind to its major oversights, logical fallacies and inferential errors. It is also discouraging that a paper riddled with glaring problems was not only published in a flagship journal, but widely cited in academic literature and praised by (often data-savvy ) journalists - with virtually no one seeing these major faults.

Statistician Andrew Gelman (2018) argues that this non-critical reception was likely a function of Mutz's affiliation with an Ivy League department and the prestige of the journal that the essay was published in (Proceedings of the National Academy of Sciences) - which gives the work such a high level of apparent credibility that many see no need to scrutinize what is going on "under the hood." This is almost certainly a factor. For instance, previous studies have shown that works by scholars affiliated with elite schools are much more likely to be accepted for publication (Peters \& Ceci 1982) -- especially in prestige journals and exercise disproportionate impact on the direction of the field (Wellmon \& Piper 2017). However, we also know that articles which conflict with prevailing priors and commitments are much more likely to be rejected on "methodological" grounds (Mahoney 1977; Armstrong 1997) and are less likely to be cited even if published (de Vries et al. 2016). Conversely, works that affirm a picture of the world that scholars are predisposed towards receive less methodological scrutiny and are more likely to be published and cited. $^{41}$

Morgan (2018b) explicitly distances himself from the idea that politics played a role in Mutz's problematic research design, etc. This position is understandable in a sense; it is important to abstain from mindreading or attributions of motives. However, it is also absolutely critical to situate this phenomenon. After all, we are not just discussing a discreet error or flaw within an overall solid work, or even a single grievously flawed work by an otherwise outstanding scholar. This work was produced and published without anyone noticing the flaws. It was widely circulated and cited with few apparently noticing the flaws. 
There is something more systemic at work when a spate of fatal defects go unnoticed, not only by the author herself, but also by the reviewers and editors, and then the myriad scholars and journalists who read and approvingly cited the work. We are talking, then, about misinformation cascades and a pattern of blindness that transcends any particular individual, institution or institutional role - affecting scholars in a range of disciplines, affecting journalists as much as academics, etc.

One factor that seems to unite all of these disparate actors, and would well-explain the observed patterns, is a particular set of political dispositions. There is an intense and near-unanimous dislike of Trump within academia and journalism -- and an assumption that his voters must have been motivated by some kind of pathology (sexism, racism, authoritarianism, etc.) or deficit (ignorance, poverty, lower cognitive sophistication, etc.). Support for Trump - and Republicans more broadly (Eitan et al. 2018) -- is viewed as an aberration that needs to be explained, while support for Hillary Clinton (and Democrats more broadly) is viewed as less worthy of examination, and is less likely to be investigated in terms of pathology or deficit. Consequently, had Mutz more accurately described her findings (i.e. immigration seemed to be a losing issue for Trump; vote choice seemed to be driven more by antipathy towards Clinton than affinity with Trump; economic issues seemed to play a critical role in vote choice) the essay would have marked a more significant contribution to the field - although it would still be a deeply flawed work. However, precisely in virtue of deflating narratives that are popular among many journalists and academics, had she more accurately described her findings, the essay likely would have been subjected to far greater scrutiny, been cited far less if published at all, received far less media coverage, etc. To be clear, I am not insinuating the Mutz intentionally misdescribed her findings in order to expand the paper's reach. I am saying the same factors that would have inhibited the paper's reach had her findings been more accurately described likely also contributed to the errors being made to begin with, and subsequently going unnoticed by various gatekeepers.

Situating Mutz's essay in the larger "Trump studies" genre, what happened in this case does not seem to be particularly unique. There is a booming literature making the same kinds of claims, and the same kind of errors, on this topic. These works are making it past gatekeeping mechanisms that are supposed to control for quality and catch these straightforward oversights, errors and confounds -- in part because processes like peer review are intended to be somewhat adversarial in nature. They do not function properly in a context where authors, editors and reviewers all share a set of priors and commitments (i.e. Trump is horrible. Support for Trump is an anomaly which must be explained. Given that Trump is horrible, his support is best explained by appeal to pathology or deficit). Nor are errors that make it past the gatekeepers likely to be caught post-publication if the journalists and scholars engaging with the work share the same priors and commitments on this topic as the authors, editors and reviewers - and indeed, are eager to identify and elevate works validating a particular narrative on the phenomenon in question.

The takeaway here is not that all research on Trump is bad, but rather that the usual filtering and credibility-signaling mechanisms do not seem to be quite as reliable with respect to work on this topic. Readers should pay careful scrutiny to the claims being advanced in this literature, as well as the data and methods being deployed to advance them - particularly for those essays which seem to be getting major traction in virtue of making politically or rhetorically expedient claims.

\footnotetext{
1 There is seems to be a peculiar asymmetry on social research related to racial discourse: while it is taken for granted that many statements which seem to be about other topics can really be about race (e.g. Bonilla-Silva 2017), this principle does not seem to be reflexive.
} 
No statement that seems even tangentially related to race is understood to really be about anything else - especially if the remarks in question can be used as evidence of racism or xenophobia (in which case they must also reflect something pathological about the person who uttered them). This interpretive tendency seems to play a key role in driving uncharitable interpretations of the words and actions of Trump and (especially) his supporters.

2 Those from disadvantaged groups are often held to have higher moral standing too. As Richard Rorty described it (1994, p. 104-5):

The cultural Left has a vision of an America in which the white patriarchs have stopped voting and have left all the voting to be done by members of previously victimized groups, people who have somehow come into possession of more foresight and imagination than the selfish suburbanites. These formerly oppressed and newly powerful people are expected to be as angelic as the straight white males were diabolical.

\footnotetext{
3 e.g. Atran 2012

${ }^{4}$ Rather than promoting epistemological humility or flexibility, increased levels of knowledge and/or intelligence tend to render people significantly less likely to change their beliefs when faced with evidence or arguments that contradict them (Hatemi \& McDermott 2016, West, Meserve \& Stanovich 2012, Kahan 2013). This is in part because those who are more intellectually or rhetorically capable are just better-equipped to punch holes in inconvenient facts or arguments, or finding ways to justify 'sticking to their guns' regardless (Flynn, Nyhan \& Reifler 2017). However, experts also tend to be far more ideological in their thinking, and far more extreme in their ideological leanings, than the general public (Achen \& Bartels 2016, Kinder \& Kalmoe 2017) - most of whom are not particularly ideological (RePass 2008). Highly-educated people also tend to be more politically partisan (Joslyn \& Haider-Markel 2014) and are more likely to engage in political research and communication for the purpose of self-gratification (Hersh 2017).

5 Ideological commitments also deeply inform how researchers understand what the most pressing social problems are, what the best methods and frameworks are to understand those problems -- and ultimately, that sorts of interventions are best-suited to address agreed-upon problems (Kahan \& Braman 2006).

${ }^{6}$ Even as education can lead to greater rigidity of thought in many respects, it tends to increase confidence in our understanding of the matter at hand. This combination of factors help explain why specialists often have a lower rate of predictive success rate than "non-experts" in a given field, who are more epistemologically humble, flexible and receptive. Indeed, in the most comprehensive study of its kind to date, measuring the reliability of expertise, specialists' predictive abilities were rather abysmal across the board relative to epistemic "foxes." Those who also had a particular ideological axe to grind performed especially poorly: they were (literally) about as accurate in predicting events as a dart throwing chimpanzee (Tetlock 2017).

7 We are using Google Scholar because it has been demonstrated as being perhaps the most comprehensive measure for citation tracking - especially for the social sciences (Harzing \& Alakangas 2016). However, among other limitations, there is a "lag" between the time a citing article is published and the time that citation shows up in Google Scholar's search results. As a result, we expect that the "true" citation count for all of these works may be significantly higher than indicated here. The quoted figures should be understood as the "floor" estimate of their impact.

8 This essay also appears in Coates' bestselling anthology, We Were Eight Years in Power: An American Tragedy - and the argument presented here plays a pivotal role. The book has been cited at least 128 times so far (Google Scholar). One other way to understand the impact of Coates' thought for scholarship about the election would be to look at co-occurrence between "Donald Trump" and "Ta-Nehisi Coates" in post-2016 scholarship. More than 806 results appear (Google Scholar). ${ }^{9}$ The reason Anderson's book is not the primary subject of analysis (instead of Coates' essay) is because it was written and published just prior to the 2016 U.S. general election and is not about that election per se. However, in interviews after the election Anderson has repeatedly emphasized her conviction that the 'white rage' thesis best explains its outcome (e.g. Goodman 2017).

Anderson's book was based on a 2014 article she wrote for the Washington Post. Both the article and the book have been highly influential - both in the academy and beyond. Her book has already received at least 285 citations (Google Scholar), and the original article an additional 11 citations (Google Scholar). Checking for co-occurrence between the terms "Donald Trump" and "white rage" resulted in 248 results since 2016 (Google Scholar). As an indicator of its popular success, the original article was also liked or shared more than 383.7k times on Facebook. Therefore, given the similarity of their overall theses, mutatis mutandis, the critiques applied to Coates' essay should also be considered in evaluating the relevance of Anderson's work vis a vis the 2016 general election.

10 For an exploration of how the 'white working class' is misrepresented and misunderstood in popular discourses including as it relates to their alleged racism and xenophobia -- see Williams 2017.

11 In fact, while Trump won most income categories among whites rather decisively, including many upper-middle class and the low-range of the upper-classes, Clinton overwhelmingly won the white vote in all income brackets over $\$ 175 \mathrm{k}$ (Goldberg 2018). Trump may have (as Coates put it) "formed a broad coalition that ran the gamut from Joe the Dishwasher to Joe the Plumber to Joe the Banker" - but Joseph the derivatives trader et al. voted for Clinton.
} 
Put another way, the 2016 election was not an instance of the 'sociological wages of whiteness' pushing working class whites to unite with white elites against 'others.' In this case, the preferences of white elites seem to have been confounded. ${ }^{12}$ According to the Global Strategy Group, the other $30 \%$ of why Clinton lost includes differences between people who sat out the previous race but voted in this one (or first time voters) - who went more for Trump than Clinton in some pivotal states and districts. Also, there were those who did vote in the last election but sat this race out: decreased turnout in 2016 as compared to 2012 disproportionately (and adversely) affected Democrats in key districts and states. These suggest an "enthusiasm deficit" among Democratic constituencies was the key driver of the 2016 electoral outcome, beyond Democratic defections.

13 Obama himself has suggested that he likely would have won against Trump (Schmidt 2016) and blamed Clinton's loss on her campaign taking key votes for granted (Thrush \& McCaskill 2016). Our analysis suggests that Obama's story fits much better with the available data than many popular narratives within the social science literature.

${ }^{14}$ According to Gallup, even two years into Trump's presidency Barack Obama has remained America's 'most admired man' - and Michelle Obama has emerged as America's 'most admired woman' (Jones 2018).

15 Most of the 'lost' Republican white votes did not go to Hillary Clinton. They went to third-party candidates instead. This is further evidence that the electoral outcome was not driven by antipathy for Obama, or even support for Trump, but largely by public aversion to Hillary Clinton.

16 Most prominent white supremacists did strongly support Trump (e.g. Holley \& Larimer 2016). However, just as the endorsement of prominent neocons didn't entail that most Clinton supporters were neocons or neocon sympathizers, the support Trump got from white supremacists does not mean most Trump voters were, themselves, white supremacists or sympathizers. Put another way, while most ethnic nationalists likely did vote for Trump (just as most neocons likely did vote for Clinton), it would be a mistake to assume that they represent his primary base - especially in light of the aforementioned confounds.

17 An analysis by Kriner \& Shen (2017) suggests that Clinton may have lost because of her hawkishness. Their analysis suggests that the areas that flipped from Obama to Trump suffered the most casualties from recent U.S. wars abroad. Even controlling for race, gender and other popular explanations, this relationship remains significant. They posit that Hillary's pronounced support for past interventions (Yugoslavia, Afghanistan, Iraq, Libya) and declared intent to escalate U.S. involvement in Syria, Ukraine and elsewhere during her term was unappealing to those sectors of American society that have experienced loss from war - especially relative to Trump's campaign position of disentangling from the affairs of other nations and focusing on "America First."

18 For elaboration on this point about the difficulties of causal inference as it relates to race, and a more effective ways to operationalize the concept, see Sen \& Wasow 2016.

${ }^{19}$ As it relates to the primaries, Trump received more votes against him than any other successful nominee on record. He also received the lowest share of overall primary votes in nearly half-a-century (Bump 2016).

20 Given the pedigree of the Monkey Cage blog, I initially reached out to its editors to express my concerns with Wood's piece. While they privately acknowledged that there may be serious methodological and inferential flaws with the essay, they declined to issue a correction or retraction - nor would they commission a rejoinder. Instead, it was suggested that even if this particular study suffered from fatal defects, Wood was still right in a sense because there is plenty of other research, albeit not cited anywhere in Dr. Wood's essay, which seems to corroborate his broad claim that racism was a key driver of support for Trump. They forwarded another study to underscore this point. This work is analyzed in Appendix I; it does not vindicate Wood's claim. But of course, even if it had, this would not have justified the oversights on the part of Wood and the editors in bringing this flawed piece of research to press. Indeed, in many respects the response from the Monkey Cage seems to underscore this essay's central concern: deep problems were essentially overlooked because the findings conformed with a picture of the world that editors ex ante viewed as "correct."

21 As with any scale-based analysis, a good deal rests on which variables are selected to define concepts like "authoritarianism." For instance, a recent study in Personality and Individual Differences finds that both Trump and Clinton supporters seem to be driven by support for authoritarianism - albeit different strains of authoritarianism and to different degrees (Ludeke, Klitgaard \& Vitriol 2018). Within the Democratic coalition, Clinton supporters were shown to be dramatically more authoritarian across the board than Sanders voters. In terms of the general election, the authors' "authoritarian submission" scale predicted support for Clinton over Trump, while the other two variants on authoritarianism (conventionalism, authoritarian aggression) predicted support for Trump. See also: Wronski et al. 2018. 22 People's actions and interactions very commonly, and often sharply, diverge from their espoused values and preferences (Jerolmack \& Khan 2014). To the extent that there is not a tight correspondence between self-reported attitudes and actual racist behaviors, it becomes problematic to interpret a given action as racially motivated just because many people who carried out that action appear to be 'racist' in surveys.

23 These asymmetric approaches to analysis - using a particular method to explore one factor (authoritarianism), and then another method to explore another factor (racial attitudes), although the same method could be used for both; or else analyzing Republicans one way and Democrats another way when they could be analyzed and explained in the same terms 
- this is precisely what Latour highlighted and warned against in his seminal 2004 essay, "Why Has Critique Run Out of Steam" (Wood is guilty of both forms of asymmetrical analysis in his essay).

24 There is evidence that 'racist' views were also fairly common among Clinton supporters (e.g. Voorhees 2016).

${ }_{25}$ Because Wood's study was not designed to compare the relative significance of these factors among Republican voters but instead to test whether these factors made one more likely to vote Democrat or Republican -- even the more careful description of his findings presented above would remain somewhat prejudiced by the extreme drop in the SRS indicators among Democrats. In order to eliminate this effect, Wood could run a multivariate regression testing income, symbolic racism and authoritarianism restricted only to Republican voters across time.

${ }^{26}$ A scale which would likely predict support for Trump over Clinton far better than racism or authoritarianism might include measures for "opposition to the status quo," "opposition to the political establishment," "desire for major social change," and/or "distrust of major social institutions." Indeed, Dr. Wood's own data suggests that the antipathy between Trump voters and social elites was mutual: "the degree to which the wealthy disdained the 2016 Republican candidate was without historical precedent." For recent works elaborating on these points see: Grossman \& Thaler 2018; Hahl, Kim \& Zuckerman-Sivan 2018.

27 There are model syllabi being prominently circulated and widely put to use for teaching entire college courses about how the election of Trump is "a product of the American lineage of racism, sexism, nativism, and imperialism" (e.g. Connolly \& Blain 2016). Again, it is taken for granted that those who voted for the Republican candidate must have been driven by some kind of moral depravity, false consciousness or other character flaws - and the purpose such courses seem to be to reinforce this view of the world in the minds of students, and equip them to better advance this narrative outside the classroom. There seems to be no robust or good-faith engagement with confounds or alternative explanations on these syllabi.

${ }^{28}$ Of course, ethnographic research is just as susceptible to bias of study design as quantitative or historical analyses - for instance, in the selection of which cases to study, which anecdotes to include or omit, how these anecdotes are edited and framed, etc.

29 The overwhelming majority of voters, regardless of their political affiliation (or even their education level), seem to possess very little knowledge about the particular candidates or issues they are voting on. Indeed, most seem to lack even a rudimentary understanding of fundamental civic institutions and processes (Somin 2016). In other words, it is unlikely that most of those who vote for the candidates and policies Hochschild approves of are significantly more rational or politically informed than those who do not. Although there are studies that ostensibly "prove" that Trump voters are more susceptible to, and influenced by, "fake news" - many of these studies suffer from the same glaring defects as the works considered here (e.g. Philips 2018).

30 For the reference, Sides' essay has so far been cited at least 22 times (Google Scholar).

${ }^{31} \mathrm{~A}$ big assumption of Sides' analysis is that voters' opinions on the issues in question have remained virtually static since 2011. Sides was forced to assume attitude stability because the Voter Study Group simply does not have the relevant data for the period from 2013- 15 (p. 9). However, this foundational assumption is likely untrue. Wood's ANES data suggest that Republicans and (especially) Democrats did change their views on these issues over that period. In particular, all voters became less likely to endorse symbolic racism. Mutz (2018) finds that voters across the political spectrum also grew warmer on immigration. This is a significant problem for Sides' research design, and likely distorted his findings.

${ }^{32} \mathrm{As}$ we have previously shown in our analysis of Coates, it is entirely possible that Trump's rhetoric was actually a significant drag on his candidacy among white voters. While most of those alienated from Trump did not vote for Hillary Clinton due to her own undesirability among this constituency, many of them did defect to third-party candidates McMullin and Johnson. Figure 6 shows that these candidates overwhelmingly drew their support from those who voted for Romney in 2012.

33 With respect to the final component of Mutz's paper -- an excursus on the role of education in the 2016 U.S. Presidential Election -- readers are encouraged to see my standalone essay on this topic (al-Gharbi 2019b).

${ }^{34} \mathrm{An}$ analysis of search trends about "anxiety" carried out just prior to the 2016 election suggested that anxiety levels were highest in many of the states that ultimately flipped for Trump. The two strongest correlates with anxiety seemed to be the concerns about an economic recession and the opioid abuse epidemic (Stephens-Davidowitz 2016).

35 It is worth noting that many of the studies that Mutz relied on in justifying her definition and use of the SDO construct are small $\mathrm{N}$ studies -- at times, mere dozens of participants -- carried out primarily on convenience samples of college students (e.g. Morrison \& Ybarra 2008; Sibley et al. 2007; Shook et al. 2015 - see the Mutz paper for full citations for these papers: notes $46,48,49)$. These kinds of studies are well-established as unreliable for generalizability or replication (e.g. Hanel \& Vione 2016; Peterson \& Merunka 2014; Brookshire 2013; Hruschka 2018). Consequently, the basis for her claims about SDO and its use here seem weak.

${ }^{36}$ Mutz argued, "Individual levels of SDO are known to increase when people feel threatened ( $\left.\underline{46} \underline{\underline{4}}-\underline{48}\right)$ and to decline when they feel less threatened ( $\underline{49})$. Thus, increasing levels of SDO indicate increasing group status threat." 
37 The formal logical structure of Mutz's argument would be:

$\mathrm{P} \rightarrow \mathrm{Q}, \mathrm{Q}$

$\therefore \mathrm{P}$

An analogous argument would be:

1. Smoking is one thing that can raise the risk of cancer

2. We have noticed an increase in incidences of cancer

$\therefore$ People must be smoking more.

The problem, of course, is that many things could be driving the increases in cancer. Smoking may be one of them, but so could other lifestyle changes, environmental factors, etc. One cannot logically infer anything about smoking behavior purely on the basis of increased rates of cancer -- even increased rates of lung cancer. Similarly, one cannot conclude there was an increase in perceived status threat on the basis of increased SDO.

Indeed, Mutz herself acknowledges that reverse causation is even possible: Trump voters could adopt a social dominance orientation as a way of mirroring their preferred candidate, rather than being driven to that candidate as a result of increased SDO. Mutz dismisses this possibility because she finds it implausible that Trump could cause people to change their positions in this way, due to his status as a party outsider. In fact, research shows that voters regularly adjust their positions on particular issues -- to bring them into compliance with the party line -- when those issues become highly politically-salient (Satherly et al. 2018). Pace Mutz, voters are especially likely to change their understanding of what their parties represent, and to update their own positions accordingly, in the aftermath of a major change in party leadership (Fernandez-Vazquez \& Somer-Topcu 2017) - such as the 2016 shake-up of the Republican Party. Indeed, Trump's supporters do seem to have changed their positions on a range of issues - including issues that are central to Mutz's argument (e.g. Burmila 2018; Grossman 2018a). In short, there seem to be strong reasons to believe the reverse-causality story about the increased in SDO - bracketing concerns about the possible confound between SDO and ideological leanings and the logical fallacy in her argument about the relationship between SDO and "status threat."

${ }^{38}$ For the reference, here are the prompts for the cross-sectional questions on trade, China and immigration -- as defined in Mutz's supplemental materials:

China as opportunity:

"These days, there are different views about China. Some people see China as more of an opportunity for new markets and economic investment, while others see it as a threat to our jobs and security. Still others are somewhere in between. Which view is closer to your own?" (three-point scale).

Support for immigration:

"Please indicate whether you favor or oppose each of the following proposals addressing immigration:

(i) provide a path to citizenship for some illegal aliens who agree to return to their home country for a period of time and pay substantial fines

(ii) increase border security by building a fence along part of the US border with Mexico

(iii) return illegal immigrants to their native countries" (mean of three five-point scales).

Support for international trade:

"Do you favor or oppose the federal government in Washington negotiating more free trade agreements?"

"Thinking about the increasing amount of trade between the United States and other countries, do you think this has helped the US economy, hurt the US economy, or not affected the US economy?"

Mean of two items on five-point scales

${ }^{39}$ From the supplementary material:

"Government should spend more of our taxes providing a social safety net for all Americans."

"Federal taxes should be cut, even if it means cutting back on government programs and services" (mean of two five-point scales).

al-Gharbi, Musa (2018). "Race and the Race for the White House: On Social Research in the Age of Trump."

The American Sociologist (49)4: 496-519.

p. 34 
40 Relevant to this discussion, Mutz's work shows that, for most, the workplace is a major site for cross-cutting political networks (Mutz \& Mondak 2006). Unfortunately, academia is a stark exception to this rule. In social science fields, progressives outnumber conservatives 10:1 (al-Gharbi 2018). Similar patterns hold with respect to journalism (al-Gharbi 2017d). As Mutz's work shows, this homogeneity can have important and adverse consequences vis a vis problem solving and knowledge production (Mutz 2006; Goldman \& Mutz 2011). Ironically, the uncritical reception of Mutz's own deeplyflawed PNAS paper is a great example of the kinds of problems that can arise given a dearth of ideological diversity.

41 Pace Gelman, there are many examples of work from scholars affiliated with less prestigious schools, and publishing in less prestigious places, receiving the same uncritical reception in virtue of their work lending credence to narratives that journalists and scholars are keen to advance. Consider the case of "The Trump Effect: How 2016 Campaign Rallies Explain Spikes in Hate" (Feinberg, Branton \& Martinez-Ebers 2019a). The authors are affiliated with non-elite schools (Texas A\&M, University of North Texas). The article was not published in a journal at all, but is a working paper hosted by University of North Texas.

The study purported to show a $226 \%$ increase in hate crimes in communities that hosted Trump rallies. That is, comparing places within a state where Trump held rallies vs. communities where he did not, the researchers observed significantly higher levels of hate crimes in the former as compared to the latter. This was described as an "increase" in hate crimes (they did not look longitudinally, for instance comparing levels of hate crimes in 2015-6 to levels of hate crimes in those same communities in 2013-4).

The problem, however, is that politicians tend to hold rallies in relatively large and populous cities/ towns. These tend to have more crime of all varieties, including hate crimes, as compared to other communities (much larger and more heterogenous populations bumping up against one-another with weaker communal ties between them). When one controls for the larger populations and increased prevalence of hate crimes in these towns in general -- irrespective of election years or political rallies -- then the effect goes away entirely. Indeed, relying on the same flawed model as these researchers, testing the effect of Democratic campaign events, it would appear as though Clinton rallies actually led to an even bigger "increase" in hate crimes than Trump's (Lilley \& Wheaton 2019)!

Moreover, many communities (especially those in swing states/ districts) hosted rallies from both major-party candidates. This makes it difficult to attribute any observed difference in hate crimes to Trump in particular. The fact that the authors excluded from the outset that Clinton rallies could have contributed to the observed effect suggests that the authors were fishing for a particular type of finding rather than testing the effects of political rallies per se.

Had the researchers run symmetrical analyses for both Trump and Clinton rallies, they would have seen that - according to their model -- Clinton seemed to be driving hate crimes even more than Trump. This likely would have caused them to rethink their model, and probably would have allowed them to catch their error (failing to sufficiently control for population sizes and baseline differences in hate crimes across communities irrespective of political cycles). Instead, they only tested the effect of Trump rallies under the assumption that of course Clinton rallies would have no effect -- or even a negative effect -- on hate crimes. All of those who enthusiastically reported on the research seemed to be working off the same assumptions.

Consequently, an unpublished paper with obvious and grievous errors, whose data in fact suggested no relationship between political rallies and hate crimes, received widespread attention and acclaim in virtue of claiming the opposite. Their study was featured by Vox, CNN, Chronicle of Higher Education, Associated Press and myriad other outlets. Their statistics were cited on social media by Senator Bernie Sanders and Congresswoman Ilhan Omar. The authors were invited to publish a summary of their paper on Washington Post's Monkey Cage blog (Feinberg, Branton \& Martinez-Ebers 2019b) - where, as with Wood, the glaring problem with their research design went unnoticed by the editors. The Monkey Cage write-up has already been cited at least 10 times in academic literature (Google Scholar), and was shared more than 421.6k times on Facebook.

This is a case where an obviously erroneous study, composed by authors at non-elite universities - a work that was never published in a journal at all (let alone a prestigious journal) -- received widespread circulation and acclaim purely in virtue of advancing a narrative that academics and journalists were keen to find evidence for. This is not to suggest that prestige of the scholar and outlet don't matter - merely that the political/ rhetorical utility of a given work seems to matter most with respect to the proliferation of work in the "Trump studies" genre.

al-Gharbi, Musa (2018). "Race and the Race for the White House: On Social Research in the Age of Trump."

The American Sociologist (49)4: 496-519.

p. 35 


\section{ACKNOWLEDGEMENTS}

There were many people who provided essential feedback and advice for this work at different stages in its development. It would be impossible to thank everyone. However, I would be remiss if I did not flag a handful of scholars who were particularly important for bringing this essay to fruition. At my home department, Columbia University Sociology, Shamus Khan and Diane Vaughn played critical roles in helping me develop and refine the argument and framing. Daniel D'Amico of Brown University's Political Theory Project also provided very helpful feedback and encouragement in the formative stage of this project. Finally, I would like to thank Heterodox Academy for workshopping the paper with a group of scholars from different disciplinary and ideological backgrounds. I am particularly indebted to Jonathan Haidt (NYU Stern), Deb Mashek (Psychology, Harvey Mudd), Chris Martin (Sociology, Emory University) and Raffi Grinberg (Carroll School of Management, Boston College) for their questions, comments and criticisms in that process.

\section{REFERENCES}

Abbott, Andrew. 1988. The System of Professions: An Essay on the Division of Expert Labor. Chicago, IL: University of Chicago Press.

--- 2016. Processual Sociology. Chicago, IL: University of Chicago Press.

--- 2018. "Varieties of Normative Inquiry: Moral Alternatives to Politicization in Sociology." The American Sociologist. DOI: 10.1007/s12108-017-9367-8.

Achen, Christopher \& Larry Bartels. 2016. Democracy for Realists: Why Elections Do Not Produce Responsive Government. Princeton, NJ: Princeton University Press.

Atran, Scott. 2012. "God and the Ivory Tower." Foreign Policy. August 6.

Alexander, Scott. 2016. “You’re Still Crying Wolf.” Slate Star Codex. November 16.

Anderson, Carol. 2014. "Ferguson Isn't About Black Rage Against Cops. It's About White Rage Against Progress." Washington Post. August 29.

--- 2017. White Rage: The Unspoken Truth of Our Racial Divide. New York, NY: Bloomsbury USA.

Avishai, Orit, Lynne Gerber \& Jennifer Randles. 2013. "The Feminist Ethnographer's Dilemma: Reconciling Progressive Research Agendas with Fieldwork Realities." Journal of Contemporary Ethnography 42(4): 394-426.

Ball, Molly. 2017. “On Safari in Trump’s America.” The Atlantic. October 23.

Bartels, Larry \& Katherine Cramer. 2018. "White People Get More Conservative When They Move Up - Not Down - Economically. Here's the Evidence." Washington Post, May 14.

Berelson, Bernard, Paul Lazarsfeld \& William McPhee. 1986. Voting: A Study of Opinion Formation in a Presidential Campaign. University of Chicago Press.

Bonczar, Thomas. 2003. "Prevalence of Imprisonment in the U.S. Population, 1974 - 2001." Bureau of Justice Statistics. August.

Bonilla-Silva, Eduardo. 2017. Racism Without Racists: Color-Blind Racism and the Persistence of Racial Inequality in America. New York, NY: Rowman \& Littlefield Publishers.

Bouie, Jamelle. 2013. “How African Americans View Immigration Reform.” The American Prospect, January 28.

Brookshire, Bethany. 2013. "Psychology is WEIRD." Slate, May 8.

al-Gharbi, Musa (2018). "Race and the Race for the White House: On Social Research in the Age of Trump."

The American Sociologist (49)4: 496-519.

p. 36 
Bump, Philip. 2016. "Trump Got the Most GOP Votes Ever - Both For and Against Him - and Other Fun Facts." Washington Post, June 8.

Burmila, Edward. 2018. "How Trump is Changing Republican Party Values.” The Week, July 24.

Chokshi, Niraj. 2018. "Trump Voters Driven By Fear of Losing Status, Not Economic Anxiety, Study Finds.” New York Times, 24 April.

Chotiner, Isaac. 2018. "Status Whoa." Slate, 24 April.

Coates, Ta-Nehisi. 2017a. "My President Was Black." The Atlantic. January/ February Issue

--- 2017b. “The First White President." The Atlantic. October Issue.

--- (2017c). We Were Eight Years in Power: An American Tragedy. New York, NY: One World.

Cohn, Nate. 2016. "Why Trump Won: Working-Class Whites." New York Times. November 9.

Connolly, N.D.B. \& Keisha Blain. 2016. “Trump Syllabus 2.0: An Introduction to the American Culture that Led to 'Trumpism.'” Public Books. June 28.

Day, Meagan. “Why Are Rich People So Anxious?" Jacobin, November 21.

Duarte, Jose et al. 2014. "Political Diversity Will Improve Social Psychological Science." Behavioral and Brain Sciences 38: 1-58.

Dunleavy, Patrick, Simon Bastow \& Jane Tinkler. 2014. "How Social Sciences Are Converging with STEM." Social Science Space. January 22.

Easterlin, Richard. 2005. “Diminishing Marginal Utility of Income? Caveat Emptor." Social Indicators Research 70: 243-55.

Easterlin, Richard et al. 2012. "China's Life Satisfaction, 1990-2010." Proceedings of the National Academy of Sciences 109(25): 9775-80.

Eitan, Orly et al. 2018. "Is Social Psychology Politically Biased? Systematic Empirical Tests and a Forecasting Survey to Address the Controversy.” Journal of Experimental Social Psychology 79: 188-199.

Engber, Daniel. 2017. "Daryl Bem Proved ESP is Real (Which Means Science is Broken)." Slate. May 17.

Eveleth, Rose. 2014. "Academics Write Papers Arguing Over How Many People Read (and Cite) Their Papers." Smithsonian. March 25.

Fang, Lee. 2015. “Clinton, Rubio, Cruz Receive Foreign Policy Advice from the Same Consulting Firm.” The Intercept. December 18.

Feinberg, Ayal, Regina Branton \& Valerie Martinez-Ebers. 2019a. “The Trump Effect: How 2016 Campaign Rallies Explain Spikes in Hate." Working Paper.

--- 2019b. “Counties that Hosted a 2016 Trump Rally Saw a 226 Percent Increase in Hate Crimes." Washington Post, 22 March.

Fernandez-Vazquez, Pablo \& Zeynep Somer-Topcu. 2017. “The Informational Role of Party Leader Changes on Voter Perceptions of Party Positions." British Journal of Political Science. DOI:10.1017/S0007123417000047

Foa, Roberto. 2016. “It’s the Globalization, Stupid." Foreign Policy. December 6.

Flynn, D.J., Brendan Nyhan, \& Jason Reifler. 2017. "The Nature and Origins of Misperceptions: Understanding False and Unsupported Beliefs about Politics.” Advances in Political Psychology 38 (S1): 127-150.

Gaouette, Nicole. 2016. “The Democrats’ Republican Moment.” CNN. July 30.

al-Gharbi, Musa (2018). "Race and the Race for the White House: On Social Research in the Age of Trump."

The American Sociologist (49)4: 496-519.

p. 37 
Gelman, Andrew. 2018. “Does 'Status Threat' Explain the 2016 Presidential Vote?” Statistical Modeling, Causal Inference and Social Science, May 14.

--- 2017. "The Piranha Problem in Social Psychology / Behavioral Economics: the 'Take a Pill' Model of Science Eats Itself." Statistical Modeling, Causal Inference \& Social Science. December 15.

al-Gharbi, Musa. 2019a. "Viewpoint Diversity is About Much More Than Politics." Heterodox Academy, 29 April.

--- 2019b. “Academic and Political Elitism." Inside Higher Ed, 27 August.

--- 2018. “Comparing Faulty Representation Across Gender, Sexuality, Race and Ideology." Heterodox Academy, 29 March.

--- 2017a. "Trump Will Likely Win Reelection in 2020.” The Conversation, 28 November.

--- 2017b. "The Democratic Party is Facing a Demographic Crisis." The Conversation, 27 February.

--- 2017c. “A Lack of Ideological Diversity is Killing Social Research.” Times Higher Education, 23 March.

--- 2017d. “The Media Bubble is Real - And Worse Than You Think.” Heterodox Academy, 27 April.

--- 2016a. "From Political Liberalism to Para-Liberalism: Epistemological Pluralism, Cognitive Liberalism \& Authentic Choice." Comparative Philosophy 7(2): 1-25.

--- 2016b. “Hillary's Atrocious Race Record: Her Stances Over Decades Have Been Painful and Wrong.” Salon, 3 April.

--- 2015a. “The Case for an Unprincipled Foreign Policy.” Wilson Quarterly 39 (3).

--- 2015b. "White People Are Not the Enemy." Salon, 25 August.

Goldberg, Zach. 2018. “Serwer Error: Misunderstanding Trump Voters.” Quilette. January 1.

Goldman, Seth \& Diana Mutz. 2011. "The Friendly Media Phenomenon: A Cross-National Analysis of CrossCutting Exposure." Political Communication 28: 42-66.

Goodman, Amy. 2017. "Emory Professor Carol Anderson on 'White Rage: The Unspoken Truth of Our Racial Divide." Democracy Now. May 5.

Graham, Carol \& Stefano Pettinato. 2001. "Frustrated Achievers: Winners, Losers and Subjective Well-Being in New Market Economies.” Brookings, January 1.

Grandin, Greg. 2016. "Hillary Clinton's Embrace of Kissinger is Inexcusable.” The Nation. August 9.

Gray, Briahna J. 2018. “The Problem With Calling Trump a Racist.” Rolling Stone. January 23.

Grossman, Matthew. 2018a. "People Are Changing Their Views on Race and Gender Issues to Match Their Party." FiveThirtyEight, October 24.

--- 2018b. “Racial Attitudes and Political Correctness in the 2016 Presidential Election." Niskanen, May 10.

Grossmann, Matthew \& Daniel Thaler. 2018. "Mass-Elite Divides in Aversion to Social Change and Support for Donald Trump." American Politics Research 46(5): 753-784.

Groves, Robert \& Emilia Peytcheva. 2008. "The Impact of Non-Response Rates on Non-Response Bias: A MetaAnalysis." Public Opinion Quarterly 72 (2): 167-89.

Hahl, Oliver, Minjae Kim \& Ezra Zuckerman-Sivan. 2018. "The Authentic Appeal of the Lying Demagogue: Proclaiming the Deeper Truth About Political Legitimacy." American Sociological Review 83(1): 1-33.

Hamid, Shadi. 2016. “There is No 'Good' or 'Bad' America.” Washington Post. November 18.

al-Gharbi, Musa (2018). "Race and the Race for the White House: On Social Research in the Age of Trump." The American Sociologist (49)4: 496-519.

p. 38 
Hanel, Paul \& Katia Vione. 2016. "Do Student Samples Provide an Accurate Estimate of the General Public?” PLoS One 11(2): $\mathrm{e} 0168354$

Harzing, Anne-Will \& Satu Alakangas. 2016. “Google Scholar, Scopus and Web of Science: A Longitudinal and Cross-Disciplinary Comparison.” Scientometrics 106(2): 787-804.

Hatemi, Peter \& Rose McDermott. 2016. “Give me Attitudes." Annual Review of Political Science 19: 331-50.

Henry, PJ \& Jamie Napier. 2017. "Education is Related to Greater Ideological Prejudice." Public Opinion Quarterly 81(4): 930-42.

Hersh, Eitan. 2017. “Political Hobbyism: A Theory of Mass Behavior.” Working Paper, 9 March.

Hochschild, Arlie. 2016a. Strangers in Their Own Land: Anger and Mourning on the American Right. New York, NY: The New Press.

--- 2016b. "I Spent 5 Years With Some of Trump's Biggest Fans. Here's What They Won’t Tell You." Mother Jones. September/ October Issue.

--- 2016c. "The Ecstatic Edge of Politics: Sociology and Donald Trump." Contemporary Sociology 45(6): 683-9.

Holley, Peter \& Sarah Larimer. 2016. "How America's Dying White Supremacist Movement is Seizing on Donald Trump's Appeal." Washington Post. February 29.

Horgan, John. 2013. “Is 'Social Science’ an Oxymoron? Will That Ever Change?” Scientific American. April 4.

Hruschka, Daniel. 2018. "You Can’t Characterize Human Nature if Studies Overlook 85 Percent of People on Earth." The Conversation, September 16.

Ioannidis, John. 2005. “Why Most Published Research Findings Are False." PLOS Medicine. August 30.

Jacobs, Tom. 2018. "Research Suggests That Racism, Sexism and Status Fears Drove Trump Voters." Pacific Standard, 24 April.

Jerolmack, Colin \& Shamus Khan. 2014. "Talk is Cheap: Ethnography and the Attitudinal Fallacy.” Sociological Methods \& Research 43(2): 178-209.

Jilani, Zaid, Alex Emmons \& Naomi LaChance. 2016. “"Hillary Clinton's National Security Advisers are a 'Who's Who' of the Warfare State." The Intercept. September 8.

Jones, Jeffrey. 2018. “Michelle Obama Ends Hillary Clinton’s Run as Most Admired." Gallup. December 27.

Joslyn, Mark \& Donald Haider-Markel. 2014. "Who Knows Best? Education, Partisanship, and Contested Facts." Politics \& Policy 42(6): 919-47.

Kahan, Dan. 2013. "Ideology, Motivated Reasoning, and Cognitive Reflection: An Experimental Study." Judgment and Decision-Making 8(4): 407-24

Kahan, Dan \& Donald Braman. 2006. "Cultural Cognition and Public Policy." Yale Law \& Policy Review 24(1): 149-72.

Kahneman, Daniel \& Angus Deaton. 2010. "High Income Improves Evaluation of Life But Not Emotional WellBeing." Proceedings of the National Academy of Sciences 107(38): 16489-16493.

Kaufmann, Eric. 2019. “Americans Are Divided by Their Views on Race, Not Race Itself." New York Times, March 18.

Khazan, Olga. 2018. "People Voted For Trump Because They Were Anxious, Not Poor." The Atlantic, 23 April.

Kinder, Donald \& Nathan Kalmoe. 2017. Neither Liberal Nor Conservative: Ideological Innocence in the American Public. Chicago, IL: University of Chicago Press.

al-Gharbi, Musa (2018). "Race and the Race for the White House: On Social Research in the Age of Trump." The American Sociologist (49)4: 496-519.

p. 39 
Koehler, Jonathan. 1993. "The Influence of Prior Beliefs on Scientific Judgment of Evidence Quality." Organizational Behavior and Human Decision Processes 56(1): 28-55.

Kriner, Douglas \& Francis Shen. 2017. "Battlefield Casualties and Ballot Box Defeat: Did Bush-Obama Wars Cost Clinton the White House?" SSRN. June 20.

Latour, Bruno. 2004. "Why Has Critique Run Out of Steam? From Matters of Fact to Matters of Concern." Critical Inquiry 30(2): 225-248.

--- 1988. Science in Action: How to Follow Scientists and Engineers Through Society. Cambridge, MA: Harvard University Press.

Lehrer, Jonah. 2009. “Accept Defeat: The Neuroscience of Screwing Up.” Wired. December 21.

Levinovitz, Alan. 2016. “The New Astrology.” Aeon. April 4.

Lilley, Matthew \& Brian Wheaton. 2019. "No, Trump Rallies Didn’t Increase Hate Crimes by 226 Percent."

Reason, 6 September.

Lincicome, Scott. 2018. “The 'Protectionist Moment' That Wasn't." Free Trade Bulletin 72.

Lozada, Carlos. 2016. “A Berkeley Sociologist Made Some Tea-Party Friends - And Wrote a Condescending Book About Them." Washington Post. September 1.

Ludeke, Steven, Camilla Klitgaard \& Joseph Vitriol. 2018. “Comprehensively-Measured Authoritarianism Does Predict Vote Choice: The Importance of Authortiarianism's Facets, Ideological Sorting, and the Particular Candidate." Personality and Individual Differences 123: 209-16.

Luthar, Suniya. 2003. "The Culture of Affluence: Psychological Costs of Material Wealth." Child Development 74(6): 1581-1593.

MacWilliams, Matthew. 2016. "The One Weird Trait That Predicts Whether You're a Trump Supporter." Politico. January 17.

Mahoney, Michael. 1977. "Publication Prejudices: An Experimental Study of Confirmatory Bias in the Peer Review System." Cognitive Therapy and Research 1(2): 161-75.

Martin, Chris. 2016. “"How Ideology Has Hindered Sociological Insight.” The American Sociologist 47(1): 115-30.

Martinez, Ruben. 2017. “A Politics of Compassion: An Interview with Van Jones." Pacific Standard. August 1.

McWhorter, John. 2015. “Antiracism, Our Flawed New Religion.” The Daily Beast. July 27.

Meadow, Tey. 2013. "Studying Each Other: On Agency, Constraint and Positionality in the Field." Journal of Contemporary Ethnography 42(4): 466-81.

Mellnik, Ted et al. 2017. “That Big Wave of Less-Educated White Voters? It Never Happened." Washington Post. May 10.

Merton, Robert. 1972. "Insiders and Outsiders: A Chapter in the Sociology of Knowledge." American Journal of Sociology 78(1): 9-47.

Morgan, Stephen. 2018a. "Status Threat, Material Interests and the 2016 Presidential Vote." Socius 4. DOI: $10.1177 / 2378023118788217$

--- 2018b. "Correct Interpretations of Fixed-Effects Models, Specification Decisions and Self-Reports of Intended Votes: A Response to Mutz.” Socius 4. DOI: 10.1177/2378023118811502

Mutz, Diana. 2018. "Status Threat, Not Economic Hardship, Explains the 2016 Presidential Vote." Proceedings of the National Academy of Sciences 115(19): E4330- 9.

al-Gharbi, Musa (2018). "Race and the Race for the White House: On Social Research in the Age of Trump." The American Sociologist (49)4: 496-519.

p. 40 
--- 2006. Hearing the Other Side: Deliberative Versus Participatory Democracy. Cambridge, UK: Cambridge University Press.

Mutz, Diana \& Jeffery Mondak. 2011. “The Workplace as a Context for Cross-Cutting Political Discourse." The Journal of Politics 68(1): 140-155.

Munafo, Marcus et al. 2017. “A Manifesto for Reproducible Science.” Nature: Human Behavior 1(21).

Norton, Ben. 2016. "Another Neocon Endorses Clinton, Calling Her '2016's Real Conservative' and 'the Candidate of the Status Quo."” Salon. June 10.

Paleologos, David et al. 2018. "Unlikely Voter Polls: Cutting Edge Research on the 'Other America."” Suffolk University/ USA Today. April 23.

Peters, Douglas \& Stephen Ceci. 1982. "Peer Review Practices of Psychological Journals: The Fate of Published Articles, Submitted Again.” Behavioral and Brain Sciences 5(2): 187-195.

Peterson, Robert \& Dwight Merunka. 2014. "Convenience Samples of College Students and Research Reproducibility.” Journal of Business Research 67: 1035-41.

Philips, Nick. 2018. “Oxford's Junk Science on Fake News.” The American Conservative. March 6.

Polanyi, Michael. 1974. Personal Knowledge: Towards a Post-Critical Philosophy. Chicago, IL: University of Chicago Press.

Randall, David. 2017. "Beach Books: 2016-7. What Do Colleges and Universities Want Students to Read Outside Class?" National Association of Scholars. May.

Ray, Raka. 2017. “A Case of Internal Colonialism? Arlie Hochschild's Strangers in their Own Land.” British Journal of Sociology 68(1): 129-33.

Reeves, Richard. 2017. Dream Hoarders: How the American Upper Middle Class is Leaving Everyone Else in the Dust, Why That is a Problem, and What to Do About It. Washington D.C.: Brookings Institution Press.

Remler, Dahlia. 2014. "Are 90\% of Academic Papers Really Never Cited? Reviewing the Literature on Academic Citations.” LSE Impact Blog. April 23.

RePass, David. 2008. "Searching for Voters Along the Liberal-Conservative Continuum: The Infrequent Ideologue and the Missing Middle." The Forum 6(2): Article 5.

Reyna, Christine. 2017. "Scale Creation, Use and Misuse." In Jarret Crawford \& Lee Jussim (Eds) The Politics of Social Psychology. New York, NY: Psychology Press. pp. 81-98.

Roarty, Alex. 2017. "Democrats Say They Now Know Exactly Why Clinton Lost in 2016." Sydney Morning Herald, May 1.

Rorty, Richard. 1994. Achieving Our Country: Leftist Thought in the Twentieth Century. Cambridge, MA: Harvard University Press.

Roy, Natasha \& Diamond Siu. 2017. “Ta-Nehisi Coates to Teach at NYU.” Washington Square News. January 31. Samuelsohn, Darren. 2016. "The Rise of Trump Studies." Politico. April 22.

Satherly, Nichole et al. 2017. 'If They Say 'Yes,' We Say 'No': Partisan Cues Increase Polarization Over National Symbols.” Psychological Science 29(12): 1996-2009.

Schmidt, Michael. 2016. “Obama Says He Would Have Defeated Trump for a Third Term." New York Times. December 26.

Sen, Maya \& Omar Wasow. 2016. "Race as a Bundle of Sticks: Designs that Estimate Effects of Seemingly Immutable Characteristics." Annual Review of Political Science 19: 499-522.

al-Gharbi, Musa (2018). "Race and the Race for the White House: On Social Research in the Age of Trump." The American Sociologist (49)4: 496-519.

p. 41 
Serwer, Adam. 2017. “The Nationalist's Delusion.” Atlantic. November 20.

Shema, Hadas. 2012. “On Self-Citation.” Scientific American. July 24.

Sherman, Rachel. 2017. Uneasy Street: The Anxieties of Affluence. Princeton, NJ: Princeton University Press.

Shi, Feng et al. 2019. "The Wisdom of Polarized Crowds." Nature Human Behavior 3: 329-336.

Sides, John. 2017. “Race Religion and Immigration in 2016," Voter Study Group, June.

--- 2013. “About The Monkey Cage.” Washington Post. September 19.

Smith, Christian. 2014. The Sacred Project of American Sociology. Oxford, UK: Oxford University Press.

Smith, Jordan. 2017. “The Education of Ta-Nehisi Coates." Chronicle of Higher Education. October 2.

Sniderman, Paul \& Philip Tetlock. 1986. "Symbolic Racism: Problems of Motive Attribution in Political Analysis." Journal of Social Issues 42(2): 129-50.

Somin, Ilya. 2016. Democracy and Political Ignorance: Why Smaller Government is Smarter. Palo Alto, CA: Stanford University Press.

Stampnitzky, Lisa. 2013. Disciplining Terror: How Experts Invented 'Terrorism.' Cambridge, UK: Cambridge University Press.

Stanovich, Keith. 2017. “Were Trump Voters Irrational?” Quilette. September 28.

Stephens-Davidowitz, Seth. 2016. "Fifty States of Anxiety." New York Times, August 6.

Struyk, Ryan. 2017. "Poll: Views of Democratic Party Hit Lowest Mark in 25 Years." CNN, 7 November.

Taleb, Nassim. 2010a. The Bed of Procrustes: Philosophical and Practical Aphorisms. New York, NY: Random House.

--- 2010b. “The Narrative Fallacy.” Black Swan: The Impact of the Highly Improbable (62-84). New York, NY:

Random House.

Tesler, Michael. 2016. "President Obama Can Thank Donald Trump and Hillary Clinton for His Growing Popularity." Washington Post. July 13.

Tetlock, Philip. 1994. "Political Psychology or Politicized Psychology: Is the Road to Scientific Hell Paved with Good Moral Intentions?” Political Psychology 15(3): 509-29.

--- 2017. Expert Political Judgement: How Good is It? How Can We Know? Princeton, NJ: Princeton University Press.

Thrush, Glenn \& Nolan McCaskill. 2016. “Obama Says Clinton Didn’t Work as Hard as He Did.” Politico, 14 November.

Times Higher Education. 2017. "New York University." 2017 World University Rankings.

Uhrmacher, Kevin, Kevin Schaul \& Dan Keating. 2016. "These Former Obama Strongholds Sealed the Election for Trump." Washington Post. November 9.

U.S. Census Bureau. 2017. "Reported Voting and Registration, by Race, Hispanic Origin, Sex, and Age, for the United States: November 2016." Voting and Registration in the Election of November 2016.

Van Bavel, Jay \& Andrea Pereira. 2018. "The Partisan Brain: An Identity-Based Model of Political Belief." PsyArXiv. January 12.

Voorhees, Joss. 2016. “New Poll Finds That Hillary Supporters Are Pretty Racist Too.” Slate. June 29.

al-Gharbi, Musa (2018). "Race and the Race for the White House: On Social Research in the Age of Trump."

The American Sociologist (49)4: 496-519.

p. 42 
de Vries, Ymkje, Anna et al. 2016. "Citation Bias and Selective Focus on Positive Findings in the Literature on the Serotonin Transporter Gene (5-HTTLPR), Life Stress and Depression." Psychological Medicine 46(14): 2971-2979.

V.V.B. 2018. “Trump Voters Were Motivated By Fear of Losing Their Status.” The Economist, April 26.

Waldow, Julia. 2018. "What Journalists Got Wrong About Voters in the 2016 Election." CNN, 27 April.

Watters, Ethan. 2011. Crazy Like Us: The Globalization of the American Psyche. New York, NY: Free Press.

Wellmon, Chad \& Andrew Piper. 2017. "Publication, Power and Patronage: On Inequality and Academic Publishing." Critical Inquiry, 21 July.

West, Richard F., Russell Meserve \& Keith Stanovich. 2012. "Cognitive Sophistication Does Not Attenuate the Bias Blind Spot." Journal of Personality and Social Psychology 103(3): 506-19

Williams, Joan. 2017. "White Working Class: Overcoming Class Cluelessness in America." Cambridge, MA: Harvard Business Review Press.

Wilson, Timothy et al. 1993. "Scientists' Evaluation of Research: the Biasing Effects of the Importance of the Topic." Psychological Science 4(5): 322-5.

Wilson, William \& Anmol Chadda. 2009. "The Role of Theory in Ethnographic Research." Ethnography 10(4): 549-64.

Wood, Thomas. 2017. "Racism motivated Trump voters more than authoritarianism." Washington Post. April 17.

Wronski, Julie, et al. 2018. "A Tale of Two Democrats: How Authoritarianism Divides the Democratic Party.” The Journal of Politics 80(4): 1384-1388.

Yglesias, Matthew. 2019. “The Great Awokening.” Vox, April 1. 